\title{
ETNIFICACIÓN, DESAHUCIO POR IMPAGO DE ALQUILERES Y DESPLAZAMIENTO RESIDENCIAL EN UNA CIUDAD TURÍSTICA INSULAR (LAS PALMAS DE GRAN CANARIA - ESPAÑA)
}

\author{
Juan Manuel Parreño-Castellano \\ Universidad de Las Palmas de Gran Canaria \\ juan.parreno@ulpgc.es \\ ORCID iD: https://orcid.org/0000-0002-1082-456X \\ Josefina Domínguez-Mujica \\ Universidad de Las Palmas de Gran Canaria \\ josefina.dominguezmujica@ulpgc.es \\ ORCID iD: https://orcid.org/0000-0001-7460-5553 \\ Claudio Moreno-Medina \\ Universidad de Las Palmas de Gran Canaria \\ claudio.moreno@ulpgc.es \\ ORCID iD: https://orcid.org/0000-0002-3067-5696
}

Recibido: 08/03/2021; Aceptado: 18/10/2021; Publicado: 10/12/2021

Cómo citar este artículo/citation: Parreño-Castellano, Juan Manuel; Domínguez-Mujica, Josefina; Moreno-Medina, Claudio (2021). Etnificación, desahucio por impago de alquileres y desplazamiento residencial en una ciudad turística insular (Las Palmas de Gran Canaria - España). Estudios Geográficos, 82 (291), e081. https://doi.org/10.3989/estgeogr.202192.092

\begin{abstract}
RESUMEN: Las Palmas de Gran Canaria (Canarias) es una capital insular que, dada su especialización urbano-turística, atrae visitantes, turistas y migrantes extranjeros. En el cambio de siglo, durante el periodo de expansión económica, se incrementaron los flujos de inmigración laboral y afectaron, especialmente, al espacio central de la ciudad y al entorno de su área litoral de ocio. Sin embargo, a partir de la crisis económica del año 2008 y posteriores, estos espacios centrales, que habían constituido las áreas preferentes de residencia de la población extranjera, vieron multiplicarse los desahucios por el impago de rentas. Con el proceso de recuperación económica, desde 2014, esta tendencia se ha mantenido. Este trabajo pretende, en primer lugar, analizar la relación espacial que parece existir entre la presencia de población nacida en el extranjero y los procesos de desahucio por impago de alquileres entre 2008 y 2017. En segundo lugar, estudiar el desplazamiento residencial de este colectivo, que se produce en paralelo al incremento de los precios y lanzamientos de las viviendas en alquiler y, por último, indagar en el proceso de sustitución residencial por origen que parece acompañarlo. La combinación de datos que proporcionan las Estadísticas del Padrón Continuo, sobre población nacida en el extranjero, y el Registro del Servicio Común de Notificaciones y Embargos de Las Palmas de Gran Canaria, sobre desahucios, nos ha permitido realizar un análisis cartográfico y estadístico con estos propósitos.
\end{abstract}

PALABRAS CLAVE: Etnificación, Ciudades insulares, Turistificación, Mercado Internacional de la Vivienda, Vivienda en Alquiler, Lanzamientos Judiciales.

\section{ETHNICIZATION, EVICTIONS FOR NON-PAYMENT OF RENTS AND RESIDENTIAL DISPLACEMENT IN AN ISLAND TOURIST CITY (LAS PALMAS DE GRAN CANARIA - SPAIN)}

ABSTRACT: Las Palmas de Gran Canaria (The Canary Islands) is an island city which attracts visitors, tourists, and foreign immigrants due to its urban-tourism specialization. In the turn of the century, during the period of economic expansion, the flows of labour immigrants increased and especially affected the central space and the coastal leisure area of the city. However, since the 2008 economic crisis and onwards, in these central districts that became preferential areas for the residence of foreign population, grew the evictions due to the non-payment of rents. With the process of economic recovery, since 2014, this trend continued. This study aims to analyse, first, the spatial relationship that seems to exist between the presence of population born abroad and eviction processes between 2008 and 2017. Second, study the residential displacement of this group that occurs in parallel to the increase of rents and evictions and, third, investigate the process of residential substitution by origin that seems to accompany it. The data combination provided by the Statistics of the Continuous Register on population born abroad and by the Registry of the Common Service of Notifications and Embargoes on evictions has allowed us to carry out a cartographic and statistical analysis with these purposes.

KEY WORDS: Ethnicization, Island Cities, Touristification, International Housing Market, Rental housing, Evictions. 


\section{INTRODUCCIÓN}

Tras el gran impacto de la crisis financiero-inmobiliaria iniciada en 2008 en los hogares, en las viviendas y, por extensión, en las ciudades españolas, asistimos a un proceso de reconfiguración urbana en la llamada poscrisis, desde el año 2014 hasta, al menos, el momento de aparición y desarrollo de la pandemia de 2020. En este último periodo, los procesos de elitización residencial que venían afectando a los centros urbanos de algunas ciudades han ido acompañados por un aumento de la turistización y el "urban overtourism" (Nilsson, 2020), el incremento de los niveles de inversión en la planta residencial para uso turístico (Brossat, 2019), la creciente presencia de nuevos fondos y agentes inmobiliarios y el aumento de la desposesión y de la reposesión (Domínguez-Mujica, 2021), fenómenos que se manifiestan en el mayor número de desahucios por impago de rentas.

No cabe duda, por tanto, de que, con la poscrisis económica, la gentrificación turística está impactando en un número creciente de ciudades. Sus causas han de buscarse en que la actividad turística desplaza a los residentes, por el incremento que ocasiona en el alquiler y en el precio de los inmuebles, o por el hecho de que genera espacios en los que éstos pierden recursos y referencias (Cocola-Gant, 2018; Cocola-Gant y Gago, 2019; Gotham, 2005; Sequera Fernández, 2020). Entre los grupos de residentes más afectados por esta dinámica cabe destacar a los inmigrantes laborales extranjeros, cuyo número se ha incrementado notablemente desde el cambio de siglo y cuya presencia, en áreas urbanas consolidadas, jugó un papel decisivo para garantizar un valor inmobiliario relativo para aquellas propiedades obsoletas, que contaban con menores posibilidades de rentabilidad en el mercado de la vivienda. Este grupo, como en general los hogares con menores recursos en las áreas gentrificadas, está siendo afectado especialmente por procesos de desplazamiento y de desahucio.

El objetivo general de este trabajo es ofrecer un ejemplo de las transformaciones anteriormente mencionadas a partir de un caso de estudio, paradigmático a este respecto, el de la ciudad de Las Palmas de Gran Canaria, donde, desde el cambio de siglo, se incrementó notablemente el flujo de turistas y migrantes extranjeros hacia ciertas zonas urbanas, especialmente, hacia el entorno de su principal área de ocio, la playa de Las Canteras y aledaños. Se aprecia en estas zonas un gran dinamismo del mercado del alquiler, con transacciones inmobiliarias e inversiones, en ocasiones de carácter internacional, de índole turístico-residencial, que se han intensificado tras la recesión de los años de la crisis. A la par, las tensiones en el mercado inmobiliario han devenido en procesos de desahucio que parecen haber afectado especialmente a la población de origen extranjero.

En consecuencia, el presente trabajo defiende tres hipótesis centrales. La primera, la de que los desahucios de las viviendas en alquiler han afectado especialmente a la población de origen extranjero no comunitario, tanto en el periodo de crisis como en el de la subsecuente recuperación. La segunda es que, en el reciente periodo de poscrisis, se han originado además dinámicas elitizadoras en algunos espacios de la ciudad que parecen estar incidiendo en la expulsión de este colectivo. Y, la tercera es que este desplazamiento ha llevado parejo la sustitución de unos residentes de origen extranjero por otros, lo que ha generado una estratificación de la población extranjera según origen étnico y niveles de renta. En conclusión, analizamos, en términos comparativos, la relación espacial que se da entre población extranjera y procesos de desahucio y desplazamiento residencial en las etapas de crisis y de recuperación económica, con la consiguiente reconfiguración urbana que originan los procesos de acumulación por desposesión y reposesión.

\section{ESTADO DE LA CUESTIÓN}

La década que antecede al año 2008 se caracterizó por el desarrollo de un modelo económico basado en el crecimiento del parque de viviendas y de la superficie construida en España (Burriel de Orueta, 2014; Fernández-Cuesta del Río, 2015). Este crecimiento se sustentaba, por un lado, en el incremento de la deuda privada de sociedades y particulares gracias a la financiarización productiva y, por otro, en el aumento de la población debido a la llegada de un numeroso contingente de inmigrantes. El crecimiento en el número de hogares y en el endeudamiento fueron los pilares de este sistema (Méndez Gutiérrez del Valle, 2013), un proceso que generó tensiones inflacionistas en la compraventa de vivienda en gran parte del territorio español, tensiones que se trasladaron al mercado del alquiler.

Este modelo económico se quebró con el estallido de la llamada burbuja inmobiliaria, lo que trajo consigo grandes dificultades para empresarios y familias. La pérdida de poder adquisitivo de muchos hogares conllevó dificultades para que pudieran afrontar el pago de las hipotecas y los alquileres de las viviendas y, como consecuencia de ello, los desahucios se incrementaron en todo el país. Al mismo tiempo, una parte de los inmigrantes que había llegado en el periodo anterior 
volvió a sus lugares de origen o reemigró, mientras que otros demostraron ser más resilientes ante una situación económica que los golpeó con especial dureza (Domínguez-Mujica, López de Lera, Ortega-Rivera y Pérez-Caramés, 2020; Gil-Alonso y Vidal-Coso, 2015).

Ante este escenario de crisis económica y social, la política económica desarrollada por el Gobierno español optó desde 2011 por mejorar la balanza exterior, en la que se incluye el turismo, y por rescatar al sector financiero. Lo primero conllevó una devaluación de los costes salariales y una precarización del trabajo con el propósito de incrementar la productividad, mientras que lo segundo supuso la internacionalización del sector inmobiliario. Esto último fue necesario para sanear a las entidades financieras, ya que agentes internacionales y grandes fondos de inversión, que eran quienes contaban con importantes capitales, se apropiaron en condiciones muy ventajosas de una buena parte de los inmuebles no vendidos o que la banca había obtenido mediante procesos de reposición (García-Lamarca, 2020; García Montalvo, 2015).

Así, los fondos de inversión, convertidos en fondos buitre, mediante la concesión de beneficios fiscales y la eliminación de barreras burocráticas, se hicieron con una parte de los activos de la SAREB (Sociedad de Gestión de Activos Procedentes de la Reestructuración Bancaria) y del resto de las entidades financieras a precios más que ventajosos, a través de instrumentos como las Sociedades Cotizadas de Inversión Inmobiliaria (SOCIMI), que han tenido como actividad principal la adquisición, promoción y rehabilitación de activos de naturaleza urbana para su arrendamiento, en un contexto de mejores perspectivas de rentabilidad (Domínguez Mujica, 2021). Gabarre de Sus (2019) ha estudiado la relación entre los paraísos fiscales y los fondos de inversión, por lo que es necesario enfocar este proceso como una nueva fase de la financiarización de la vivienda, en la que el mercado de los alquileres se ha convertido en uno de los principales mecanismos de acumulación del sector financiero de los últimos años.

Las consecuencias de este modelo para la recuperación productiva fueron una ligera mejora económica que tuvo su reflejo en la disminución de las ejecuciones hipotecarias y quiebras empresariales y un cambio en la estructura de la propiedad inmobiliaria del país, con una creciente presencia de estas sociedades inversoras internacionales. No obstante, los precios de los alquileres empezaron a crecer, especialmente en las zonas urbanas y turísticas más dinámicas, originándose lo que se ha venido a llamar como una bur- buja del alquiler (Ardura Urquiaga, Lorente Riverola y Sorando, 2021). Las causas son varias: la implantación desregulada de la vivienda vacacional (Yrigoy, 2017 y 2019), el mayor control en el mercado de las hipotecas inmobiliarias que ocasionaba que muchos no pudieran acceder a ellas (Méndez Gutiérrez del Valle, 2019), las prácticas desarrollas por las SOCIMIs orientadas a maximizar sus beneficios y la ausencia de una política de vivienda adecuada basada en alquileres públicos.

El mayor desajuste entre el precio de los alquileres de mercado y la renta de la población y la modificación de la Ley de Arrendamientos Urbanos, sobre todo en lo que se refiere a la reducción temporal de los contratos y la eliminación del derecho de tanteo en los inquilinos cuando los edificios se venden en su conjunto, aumentaron el esfuerzo en el pago y la inseguridad residencial de buena parte de la población, especialmente entre la más joven y los grupos sociolaborales de riesgo (Módenes, 2017 y 2019). El resultado ha sido un aumento importante de los desahucios de las viviendas en alquiler, desde 2015, en aquellas zonas en las que se manifestaban mejor las tensiones inflacionistas, en especial centros urbanos y espacios litorales en los que la vivienda turística se había implantado con fuerza. El papel de los grandes agentes inversores se ha mostrado como esencial en esta nueva fase de acumulación por desposesión centrada en la vivienda en alquiler (Méndez Gutiérrez del Valle, 2021; Seymour y Akers, 2020).

En este nuevo contexto, la afección sobre la población de origen extranjero fue elevada. En este sentido, se han desarrollado estudios que relacionan la evolución de la llegada de inmigrantes con el incremento de los alquileres y precios de venta de la vivienda (González y Ortega, 2013; Mussa, Nwaogu y Pozo, 2017), pero la relación de este colectivo con el impago de rentas apenas ha sido abordada.

Desde la perspectiva socio-urbana, el aumento del precio de los alquileres se ha mostrado como un mecanismo de explotación y de generación de desplazamiento residencial (Soederberg, 2018). Los procesos de gentrificación han sido estudiados en varias ciudades españolas. Salom Carrasco y Pitarch Garrido (2021) lo han hecho para determinados barrios de Valencia, caracterizando el proceso de elitización para el periodo 2014-18 en función del nivel educativo. Especialmente interesantes son los análisis que han abordado la gentrificación internacional o transnacional, como los realizados para algunas zonas centrales y turísticas de Barcelona y Madrid a partir del estudio de las pautas de localización de los flujos de inmigrantes 
según nivel educativo, que han puesto de manifiesto el incremento de la presencia de migrantes internacionales cualificados en estos espacios entre 2011 y 2017 como evidencia de una dinámica gentrificadora (López-Gay, Andújar-Llosa y Salvati, 2020). En términos parecidos, se ha estudiado la llegada de gentrificadores transnacionales jóvenes al barrio Gótico de Barcelona como proceso de reestructuración social y demográfica derivada de la dinámica de turistización de esta zona entre 2011 y 2019 (López-Gay, CocolaGant y Russo, 2021). Las repercusiones de la subida de los precios se han analizado también en el barrio de Sant Antoni en Barcelona desde la óptica de la afección a la identidad y vida comunitaria, dentro de una visión más amplia del concepto de gentrificación (Solana-Solana, Ortiz Guitart y López-Gay, 2021).

En un marco temporal más amplio, Jover y DíazParra (2020) han analizado también la dinámica gentrificadora de carácter transnacional vinculada con el desarrollo de la vivienda vacacional y el asentamiento de migrantes de estilo de vida en Sevilla, especialmente en el entorno de la Alameda de Colón. Parralejo Sánchez y Díaz-Parra (2021), empleando el índice de Marcuse, han analizado la elitización, especialmente la transnacional, y los procesos de turistización en los centros históricos de Cádiz y Sevilla, para concluir sobre el carácter dialéctico de estas dinámicas.

En este contexto, los archipiélagos españoles se han mostrado como espacios de éxito en la reconfiguración socioeconómica iniciada en 2014 , siendo la afluencia masiva de turistas en buena parte de los años de la segunda década del siglo XXI su mejor expresión. En la misma medida, los principales ámbitos urbanos de estos archipiélagos pronto acusaron también dinámicas gentrificadoras en determinados barrios, como respuesta al mercado internacional de la vivienda y al desarrollo de las viviendas vacacionales. Las Palmas de Gran Canaria es un ejemplo de estos procesos, con la peculiaridad de que muchas de las viviendas en alquiler afectadas son las que proceden de la desturistización de la ciudad -que había tenido lugar durante los ochenta y noventa- y fueron ocupadas desde mediados de los noventa por la población inmigrante (Domínguez-Mujica, González-Pérez y ParreñoCastellano, 2008; Domínguez-Mujica, González-Pérez, Parreño-Castellano y Sánchez Aguilera, 2021).

Por último, en lo que se refiere a los desahucios de la vivienda en alquiler en España, su estudio ha merecido una menor atención en relación con la que han tenido los recientes procesos de desposesión por impago de hipoteca. En algunos casos, los análisis se han hecho de una manera complementaria a los de estos últimos, predominando, desde la perspectiva del Derecho, la reflexión sobre los procedimientos judiciales y las obligaciones de tenedores e inquilinos (González Pillado, 2012). Simultáneamente, desde una perspectiva geográfica, en el caso de Baleares, Vives-Miró, Rullán y González-Pérez (2018) han analizado la distribución de los desahucios por ejecución hipotecaria e impago de alquiler en la ciudad de Palma, durante el boom inmobiliario y la posterior crisis, y han detectado que los segundos se concentran de manera especial en los espacios de gentrificación de la ciudad. Vives-Miró y Rullán (2017), además, han incluido como variable de análisis el desplazamiento que la combinación de desahucio de inquilinos, subida de renta y vivienda turística ha producido en el casco histórico de Palma. En Canarias, Díaz-Rodríguez, García-Herrera, García-Hernández, Armas-Díaz y Ginés de la Nuez (2018) han analizado los procesos de desposesión de inquilinos y, desde un enfoque de barrio, García-Hernández, Armas-Díaz y Díaz-Rodríguez (2020) han relacionado los desahucios de inquilinos en el barrio de El Toscal en Santa Cruz de Tenerife con el desarrollo de la vivienda vacacional y la gentrificación del barrio.

En otros ámbitos geográficos, también se ha analizado la relación entre el nivel económico y la diferenciación étnica con los desahucios de alquileres, como en el caso del condado de Salt Lake en Utah (EE. UU.) (Medina, Byrne, Brewer y Nicolosi, 2020; Robinson y Steil, 2020) pero, en términos generales, la relación entre migración, pérdida de la vivienda en alquiler y gentrificación ha merecido poca atención. En este contexto, este artículo intenta avanzar en esta mirada a partir del reconocimiento de la dinámica socio-urbana que acontece en espacios urbanos insulares con un importante legado turístico.

\section{FUENTES Y METODOLOGÍA}

Con la finalidad descrita anteriormente, se ha utilizado la información de dos fuentes básicas. En primer lugar, los microdatos de la Estadística del Padrón Continuo (Instituto Nacional de Estadística) referentes al periodo 2009-2018. Ello nos permite investigar acerca de las tendencias y pautas de localización de los residentes según su país de nacimiento, a nivel de sección censal y barrio en Las Palmas de Gran Canaria. En ocasiones se usa también la población extranjera como variable de análisis, pero de una manera secundaria, dado que las cifras de este colectivo están condicionadas por los procesos de nacionalización. 
Por otra parte, los cambios que se han producido en el número y delimitación de las secciones censales a lo largo de este periodo nos han obligado a referir los datos a la delimitación censal de 1 de enero de 2018, con el fin de establecer comparaciones temporales sobre la misma base territorial, algo que sin duda reviste cierta complejidad.

En segundo lugar, nos valemos de los datos del Servicio Común de Notificaciones y Embargos de Las Palmas de Gran Canaria para analizar la incidencia territorial de los procesos judiciales de desahucio por impago de rentas a lo largo del mismo periodo de estudio. Los distritos judiciales españoles de mayor tamaño demográfico cuentan con los denominados Servicios Comunes, que centralizan la actuación de los diferentes juzgados y realizan los actos de notificación y ejecución. Los Servicios Comunes en Canarias utilizan un sistema de gestión procesal digital denominado Atlante al cual tuvimos acceso.

Los desahucios se instrumentalizan a través de juicios verbales y, fundamentalmente, apelando al artículo 250.1.1 de la Ley $1 / 2000$ de 7 de enero de Enjuiciamiento Civil, reformada con la Ley 19/2009 de 23 de noviembre de medidas de fomento y agilización procesal del alquiler y de la eficiencia energética de los edificios, que establece el impago de renta como causa de esta privación. Además de los juicios verbales por impago de rentas, que es la situación más frecuente, también se ejecutan procedimientos por cesiones en precario (250.1.2); tutela sumaria de la tenencia de un inmueble (250.1.4); reclamación de titulares de derechos reales (250.1.7) y de cantidades de menor cuantía (250.2). Las demandas por ocupación en precario, por tutela sumaria de tenencia o por restablecer derechos reales suelen orientarse a recuperar inmuebles ocupados sin relación contractual previa (Parreño-Castellano, Domínguez-Mujica, Armengol Martín, Boldú Hernández y Pérez García, 2019). Todo ello nos informa de la diversidad de situaciones que podemos encontrar tras un lanzamiento judicial.

Dado que estos procedimientos tienen diferentes momentos procesales, en ocasiones los procesos iniciados no concluyen en desahucio, por lo que la información utilizada se refiere a las acciones judiciales concluidas con resultado de expulsión del inquilino. A este respecto, también hay que recordar que existen otras situaciones que implican pérdida de la vivienda arrendada sin que medie un procedimiento judicial.

Todos los registros incluidos en el sistema de gestión procesal Atlante II fueron consultados, aunque sólo los relativos a personas físicas. La base de datos contiene los siguientes campos: tipo de titular afectado (persona física o jurídica), diligencia que se lleva a cabo, tipo de procedimiento, dirección postal del bien intervenido, fecha de entrada, fecha de actuación y estado. La posibilidad de disponer de la dirección postal nos permitió que, tras la conveniente depuración de los registros, pudiéramos geolocalizar los expedientes en un Sistema de Información Geográfica.

Esta fuente de información se completó con los datos oficiales sobre lanzamientos relacionados con la ley de arrendamiento urbano que publica a escala de provincia y partido judicial el Consejo General del Poder Judicial para el periodo 2013-19 y los que también elabora este organismo relativo a sentencias por impago de rentas, fianzas y prórroga desde 2008. De manera complementaria se usaron otras fuentes relativas a evolución del precio de los alquileres, presencia de vivienda vacacional en Las Palmas de Gran Canaria y tenencia de la vivienda por nacionalidad.

La metodología se ha fundamentado en el análisis cartográfico y estadístico. La geolocalización de los desahucios nos posibilitó conocer la incidencia intraurbana en términos absolutos y relativos (índice de desahucio), a escala de sección y barrio en Las Palmas de Gran Canaria. Posteriormente, se llevó a cabo un análisis de correlación estadística entre esta información y la de la distribución de la población nacida en el extranjero, a escala de sección censal, con el fin de apreciar el nivel de asociación conjunta.

Por último, se abordó el estudio de los cambios en la distribución de la población analizada por país de origen a escala de distrito y sección para los años 2009, 2014 y 2018, utilizándose esta última como escala de referencia, si bien hubo que considerar las modificaciones en las delimitaciones administrativas que se habían producido en estos tres años. El análisis se completó, a nivel de municipio, con los datos de altas y bajas por país de origen, procedentes de la Estadística de Variaciones Residenciales para el periodo considerado, lo que nos permitió aproximarnos a la caracterización de procesos de desplazamiento y sustitución.

\section{RESULTADOS Y DISCUSIÓN}

\subsection{Evolución temporal del desahucio de la vivienda arrendada. Un fenómeno vinculado a la reciente re- cuperación económica.}

Desde 2013, el Consejo General del Poder Judicial publica datos estandarizados a escala de provincia y 
partido judicial sobre lanzamientos practicados como consecuencia de procedimientos judiciales relacionados con la Ley de Arrendamientos Urbanos. Los datos registrados manifiestan que entre 2013 y 2019 se han practicado como promedio unos 36.210 lanzamientos en España, de los que en torno al $6 \%$ se han producido en Canarias (un promedio anual de 2.172). A su vez, en el partido judicial de Las Palmas de Gran Canaria se ha registrado una cifra media de 402 procedimientos, un $18,5 \%$ de los registrados en Canarias.

FIGURA 1

LANZAMIENTOS PRACTICADOS RELACIONADOS CON LA LEY DE ARRENDAMIENTOS URBANOS EN ESPAÑA (IZQUIERDA) Y CANARIAS (DERECHA) (2013-19)


Fuente: Consejo General del Poder Judicial. Elaboración propia.

FIGURA 2

LANZAMIENTOS RELACIONADOS CON LA LEY DE ARRENDAMIENTOS URBANOS POR CADA MIL HABITANTES PRACTICADOS EN LAS PROVINCIAS ESPAÑOLAS (2013-19)

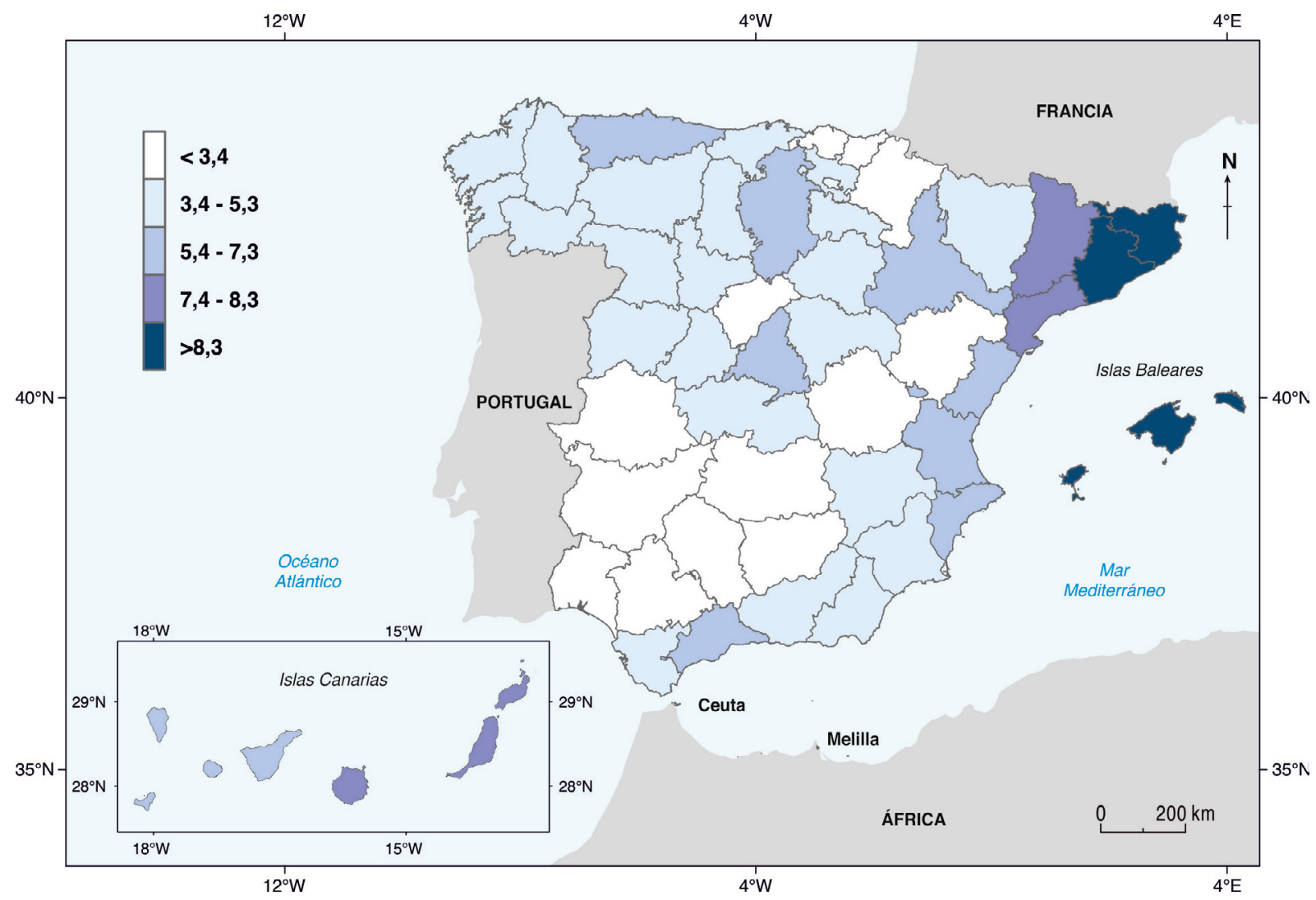

Fuente: Consejo General del Poder Judicial, INE (Padrón Continuo de Población). Elaboración propia. 
FIGURA 3

SENTENCIAS POR IMPAGO DE RENTAS, FIANZAS Y PRÓRROGA EN ESPAÑA (IZQUIERDA) Y CANARIAS (DERECHA) (2008-19)

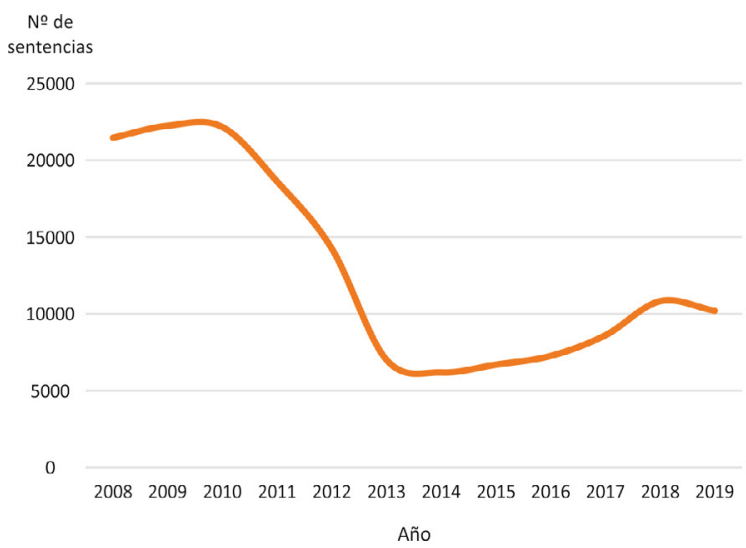

Fuente: Consejo General del Poder Judicial, INE. Elaboración propia.

Llama la atención que las cifras sean bastante estables durante todo el periodo. Los datos de España y Canarias apuntan a un descenso de los valores con el final de la crisis (2013) y la posterior recuperación (2014-16), y a un posterior crecimiento, especialmente en el caso de archipiélago (figura 1).

La distribución territorial de los desahucios vinculados a la ley de arrendamientos urbanos no es homogénea en el periodo 2013-19. A escala provincial, la incidencia por cada 1.000 habitantes ha sido especialmente elevada en las provincias catalanas, Illes Balears y Las Palmas. A estas zonas se suman otras provincias mediterráneas como las de la Comunidad Valenciana o Málaga y algunas provincias del interior y norte como Burgos, Asturias, Zaragoza o Madrid. En la Figura 2 se puede apreciar la desigual distribución de la incidencia de los lanzamientos por población, clasificada en función del valor provincial promedio $(5,4)$ y los niveles de dispersión estándar.

No contamos con datos tan precisos sobre lanzamientos practicados para años anteriores, pero otras series estadísticas permiten realizar algunas aproximaciones. Este es el caso de las sentencias por impago de rentas, fianzas o cantidades similares, y por el incumplimiento de prórrogas de vivienda arrendadas. Como cabía esperar (figura 3), la crisis económica supuso que el número de sentencias fuera muy elevado, mayor del que se registró en los años anteriores. Entre 2011 y 2013 los valores descendieron para, a partir de 2017, experimentar de nuevo un incremento, tal como hemos comentado con los datos de lanzamientos practicados. Aunque no podemos asimilar las sentencias con procesos de desahucio, debemos tener presente que la gran mayoría de las sentencias fueron estimadas total

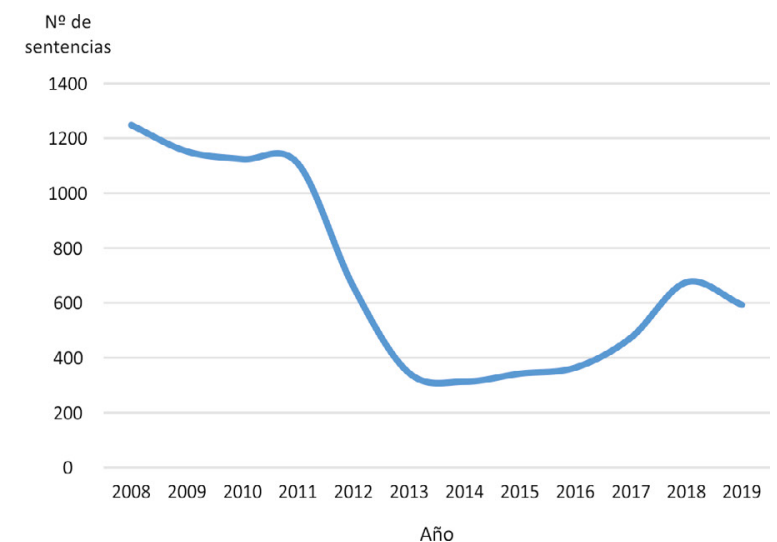

FIGURA 4

EXPEDIENTES CON RESULTADO POSITIVO DE PÉRDIDA DE USO DE LA VIVIENDA EN EL PARTIDO JUDICIAL DE LAS PALMAS DE GRAN CANARIA (2009-17)

№ de
expedientes

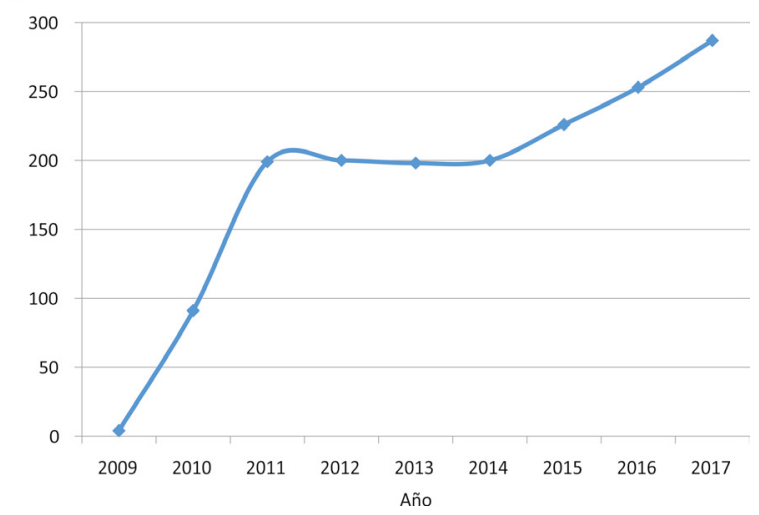

Fuente: Servicio Común de Notificaciones y Embargos. Elaboración propia.

o parcialmente. La evolución de los datos en Canarias es similar, con la particularidad de que la tendencia al descenso en el número de sentencias se retrasa a 2012, lo que se relaciona con una crisis económica más larga y profunda en el Archipiélago.

En el caso del partido judicial de Las Palmas de Gran Canaria la consulta de los expedientes en el Servicio Común de Notificaciones y Embargo nos ha permitido conocer cómo han evolucionado las cifras de pérdida de vivienda en alquiler en el periodo comprendido entre 2009-2017, a partir de los procedimientos practicados con resultado positivo. En esos años se ejecutaron 1.660 expedientes de privación de uso que terminaron con la expulsión de los inquilinos. El número de expedientes creció intensamente en los 
primeros años de la crisis, alcanzándose la cifra más elevada en 2011 (figura 4). Entre ese año y 2014 los desahucios tendieron a estabilizarse. En consonancia con lo que ocurre para el conjunto de Canarias, desde 2015 el número de desahucios de viviendas en arrendamiento ha crecido de manera espectacular, de tal manera que podemos colegir que, en el caso de Las Palmas de Gran Canaria, la mejora económica ha supuesto que los lanzamientos de vivienda en alquiler sean incluso más frecuentes (Parreño-Castellano, Domínguez-Mujica, Armengol-Martín, Pérez García y Boldú Hernández, 2018b).

Por tanto, a partir de los datos que hemos presentado, relativos a lanzamientos tramitados, expedientes con resultado positivo y sentencias sobre viviendas arrendadas, podemos concluir que los lanzamientos no se vinculan tan sólo a la crisis, sino también a la forma en que se reestructura la economía en los últimos años, en la llamada poscrisis. Es decir, la pérdida de la vivienda en alquiler es el resultado, tanto de las dificultades económicas de las familias, derivadas de una coyuntura económica adversa, como de la manera en que se ha producido la recuperación económica. La internacionalización del mercado inmobiliario del alquiler y el control de las rentas salariales han desequilibrado la relación entre los alquileres y los recursos económicos de los hogares en los últimos años y esto ha repercutido, claramente, en el aumento de lanzamientos. Esto es especialmente evidente en Canarias y, particularmente, en las Palmas de Gran Canaria, una ciudad en la que los precios de las rentas tienden a desequilibrarse cada vez más, en relación con los recursos económicos de la población.

Pero, además, las series analizadas reflejan, por otro lado, la incidencia real de las medidas anti-desahucios y de las actuaciones de política de vivienda adoptadas en estos últimos años, por lo que podemos decir, en sentido genérico, que las políticas de vivienda, puestas en marcha a diferentes niveles administrativos, no han sido capaces de paliar la dificultad de acceso a la vivienda en el último lustro.

4.2. Localización intraurbana del desahucio de la vivienda arrendada en Las Palmas de Gran Canaria. Concentración en los espacios de reciente turistización.

La información disponible, para su consulta en línea, no permite conocer la distribución de los procedimientos a una escala inferior a la del partido judicial. Hay que recurrir a explotaciones estadísticas y al análisis de los expedientes para obtener una información más precisa.
En el caso de Las Palmas de Gran Canaria, la distribución intraurbana de los lanzamientos se ha realizado a partir de los expedientes tramitados con resultado positivo entre 2009 y 2017. Las actuaciones de desahucio se han concentrado en los barrios centrales de la ciudad, situados en el istmo de Guanarteme y, de modo secundario, en el resto de los barrios centrales. No obstante, en los últimos años, los desahucios han tenido una mayor incidencia en las zonas periféricas de la Ciudad Alta (Parreño-Castellano, DomínguezMujica, Armengol-Martín, Pérez García y Boldú Hernández, 2018a).

En 89 de los 123 barrios de la ciudad encontramos algún caso de desahucio de vivienda en alquiler. Existe una fuerte concentración en los cuatro barrios situados en el entorno de las playas de Las Canteras y Alcaravaneras y el Puerto de la Luz (Santa CatalinaCanteras, Guanarteme, La Isleta y Alcaravaneras) con un $41,4 \%$ de todos ellos. Se trata de una zona que se desarrolló, principalmente, desde finales del siglo XIX y donde se concentran servicios y actividades logísticas relacionadas con el puerto y otros servicios de carácter comercial y turístico (figura 5).

En el resto del espacio central de la ciudad, el conformado por los barrios de Vegueta, Triana, Canalejas, Lugo, Ciudad del Mar, Fincas Unidas y Ciudad Jardín se ubica el $13,3 \%$ de los expedientes. Es una zona que incluye los barrios fundacionales y otros crecimientos iniciados desde mediados del siglo XIX, como ensanches de población, con una importante presencia de actividades comerciales, administrativas y de todo tipo de servicios.

Gran parte de los restantes lanzamientos se localiza en los espacios periféricos de la ciudad, en los barrios que se construyeron en los sesenta y setenta del siglo XX, con polígonos de vivienda pública o subsidiada (Schamann, Escaleritas, Las Chumberas, La Feria, La Paterna, Las Rehoyas, Miller-Mata, Casablanca III...), si bien sólo en algunos el índice relativo por la población residente alcanza valores elevados, coincidiendo con las zonas donde la vivienda de promoción pública tiene una menor presencia. En cifras absolutas, un porcentaje menor se concentra en el crecimiento urbano periférico masivo desarrollado posteriormente. Este último, aunque subsidiado en algunos casos, concentra buena parte del crecimiento urbano reciente de clase media (San Lázaro, Las Torres, Tamaraceite).

Por su parte, los Riscos históricos de la ciudad (los barrios construidos desde el siglo XVII en ladera, para albergar la población con menores recursos) presentan cifras reducidas y tan sólo cabe destacar las registradas 
FIGURA 5

PORCENTAJE DE EXPEDIENTES DE PÉRDIDA DE USO SEGÚN EL NÚMERO DE EMPADRONADOS POR BARRIOS EN LAS PALMAS DE GRAN CANARIA (2009-17)

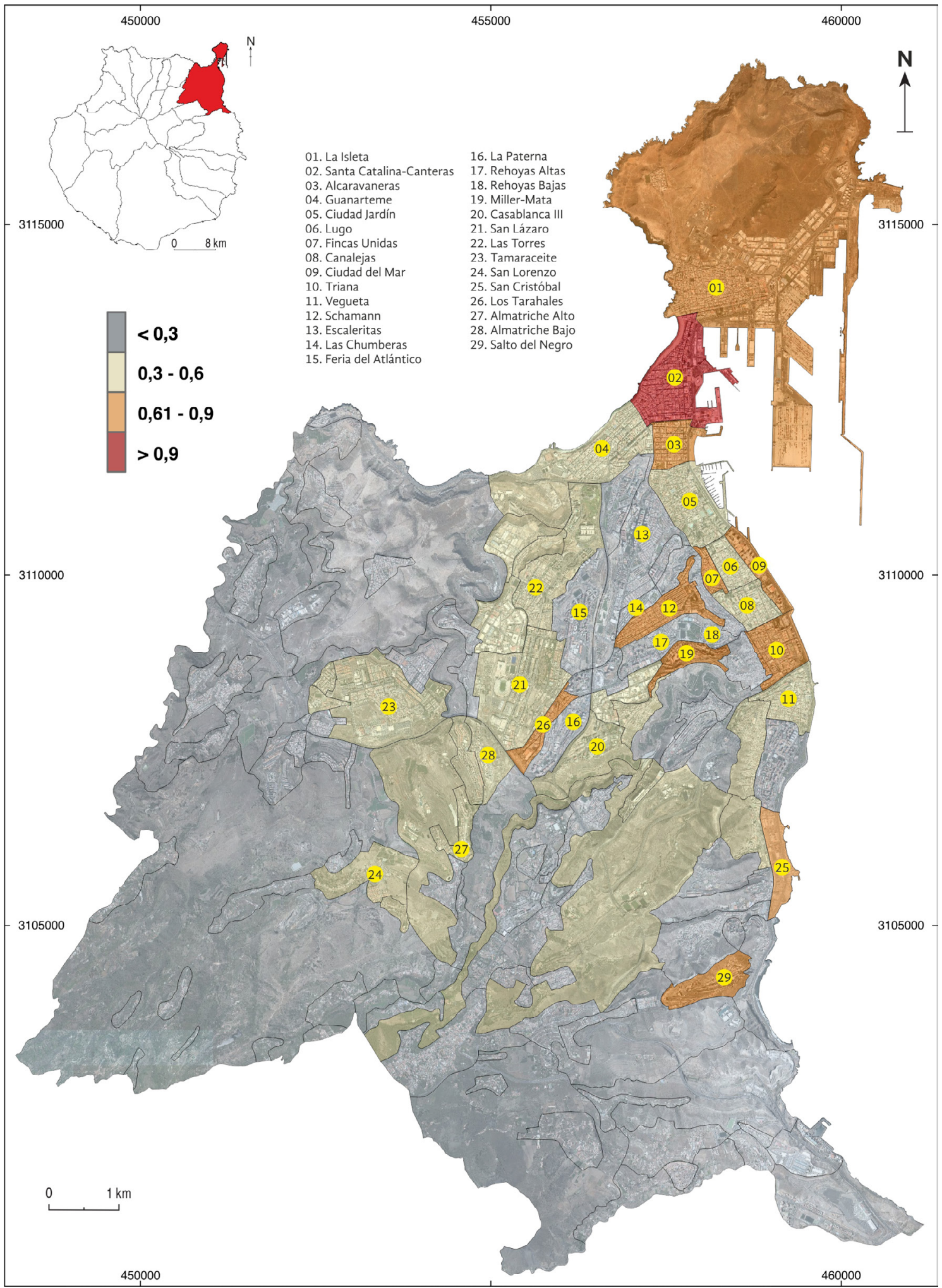

Fuente: Servicio Común de Notificaciones y Embargos del Partido Judicial de Las Palmas de Gran Canaria. Elaboración propia. 
en San José-San Juan. Lo mismo sucede en el resto de los barrios, aquellos que se corresponden con los crecimientos masivos en torno al Guiniguada, con los polígonos de vivienda del sur del municipio y con los núcleos periféricos aislados, generalmente de autoconstrucción. En ese último caso destacan, sin embargo, algunas áreas como San Cristóbal, Los Tarahales, Almatriche, San Lorenzo, etc., que, aunque en origen crecieron gracias a promociones espontáneas, han tenido en los últimos años procesos de renovación inmobiliaria o un fuerte incremento de precios. Salto del Negro es el único espacio de crecimiento espontáneo reciente con unos índices de desahucio elevados.

Por consiguiente, la localización de los expedientes registrados entre 2009 y 2017 revela, en primer lugar, una importante concentración en áreas centrales, en muchos casos espacios que habían sufrido procesos de desturistización en los años ochenta y noventa del siglo XX (Santa Catalina-Las Canteras, Guanarteme) y que ahora tienden a concentrar la vivienda vacacional y, en segundo lugar, una presencia significativa en otros barrios centrales y de la primera corona periurbana de la ciudad, la construida hasta los años ochenta del mismo siglo.

\subsection{Presencia extranjera en Las Palmas de Gran Ca- naria. Crecimiento y localización intraurbana.}

La comunidad extranjera en la ciudad de Las Palmas de Gran Canaria, cuya presencia se hallaba vinculada a la actividad portuaria y al desarrollo turístico de la ciudad, ha experimentado un importante crecimiento desde el último lustro de la década de los noventa del siglo pasado. Como consecuencia de ello, el índice de extranjería, teniendo en cuenta los nacidos en el extranjero residentes en el municipio, aumentó desde el $6 \%$ al $11,9 \%$, entre 2001 y 2008 . La crisis económica iniciada en 2008 supuso el retorno de una parte de la población extranjera a sus países de origen, el aumento de los procesos de reemigración en busca de oportunidades laborales y la nacionalización de una parte de esta comunidad. No obstante, la presencia de nacidos en el extranjero siguió ganando peso en el municipio. En 2014, cuando la crisis económica empieza a dar paso a una ligera recuperación, el índice se situaba en el 13,4\%, cifra que ha aumentado en los últimos años, llegando al 15,4\% a uno de enero de 2020.

Los extranjeros residentes en Las Palmas de Gran Canaria son de origen diverso. Tomando como referencia el uno de enero de 2018 -en función del periodo al que están referidos los datos de distribución intraurbana de los desahucios de la vivienda en al- quiler analizados en el anterior epígrafe-, algo más de la mitad de los empadronados había nacido en el continente americano, destacando los oriundos de Cuba, Colombia, Venezuela y Argentina, en orden descendente. Es un colectivo en el que se aúnan flujos migratorios relativamente recientes, como es el caso de los colombianos, con otros que hunden sus raíces en relaciones de vaivén consolidadas a lo largo de muchas décadas, como es el caso de los procedentes de Cuba y Venezuela. En cuanto a los procedentes del continente europeo, el $18,4 \%$ había nacido en la Unión Europea, destacando por lugar de origen los italianos, alemanes y británicos. El $15,6 \%$ eran oriundos de África, y de entre estos destacaban los nacidos en Marruecos. Los de origen asiático suponían un $10,9 \%$ del colectivo, siendo las cifras de europeos no comunitarios y de otras procedencias muy reducidas. En cualquier caso, la diversidad por nacionalidad o país de nacimiento es una de las características más sobresalientes, y a ella se suman las cifras más modestas de otros grupos nacionales como coreanos, hindúes, japoneses, finlandeses, senegaleses, caboverdianos y de prácticamente todas las procedencias de Sudamérica, lo que manifiesta la complejidad de los procesos inmigratorios de la ciudad, que incluye tanto inmigrantes laborales como de estilo de vida, así como su persistencia en el tiempo.

La evolución de los empadronados nacidos en el extranjero en el periodo 2009-18 por país de nacimiento presenta importantes disparidades. Aunque por continente de procedencia, solamente se ha reducido el contingente de los nacidos en África, la realidad es que el crecimiento que se ha registrado se ha concentrado en muy pocas nacionalidades. Por ejemplo, en el caso de Europa, al mismo tiempo que los nacidos en Alemania, Reino Unido, Francia o Portugal disminuyen en número, se ha producido un incremento muy elevado de originarios de Italia y, en menor medida, de países del Este (Polonia, Rumania, Bulgaria). Lo mismo cabe decir respeto a los nacidos en América, pues los originarios de Cuba, Venezuela o Colombia han crecido de forma significativa, en detrimento de otros colectivos, como los nacidos en Argentina (ver figura 6).

La magnitud de los recientes flujos migratorios ha supuesto que la presencia de los extranjeros se haya generalizado a muchas zonas de la ciudad, pero la mayor parte se han afincado en el entorno del puerto de La Luz y playa de Las Canteras, en el distrito 3 (Santa Catalina, Guanarteme, La Isleta y Alcaravaneras, fundamentalmente). Los porcentajes de residentes nacidos en el extranjero a nivel de sección censal en 2018 
DIFERENCIA EN LA CIFRA DE EMPADRONADOS NACIDOS EN EL EXTRANJERO POR PAÍS DE NACIMIENTO EN LAS PALMAS DE GRAN CANARIA ENTRE 2017 Y 2009

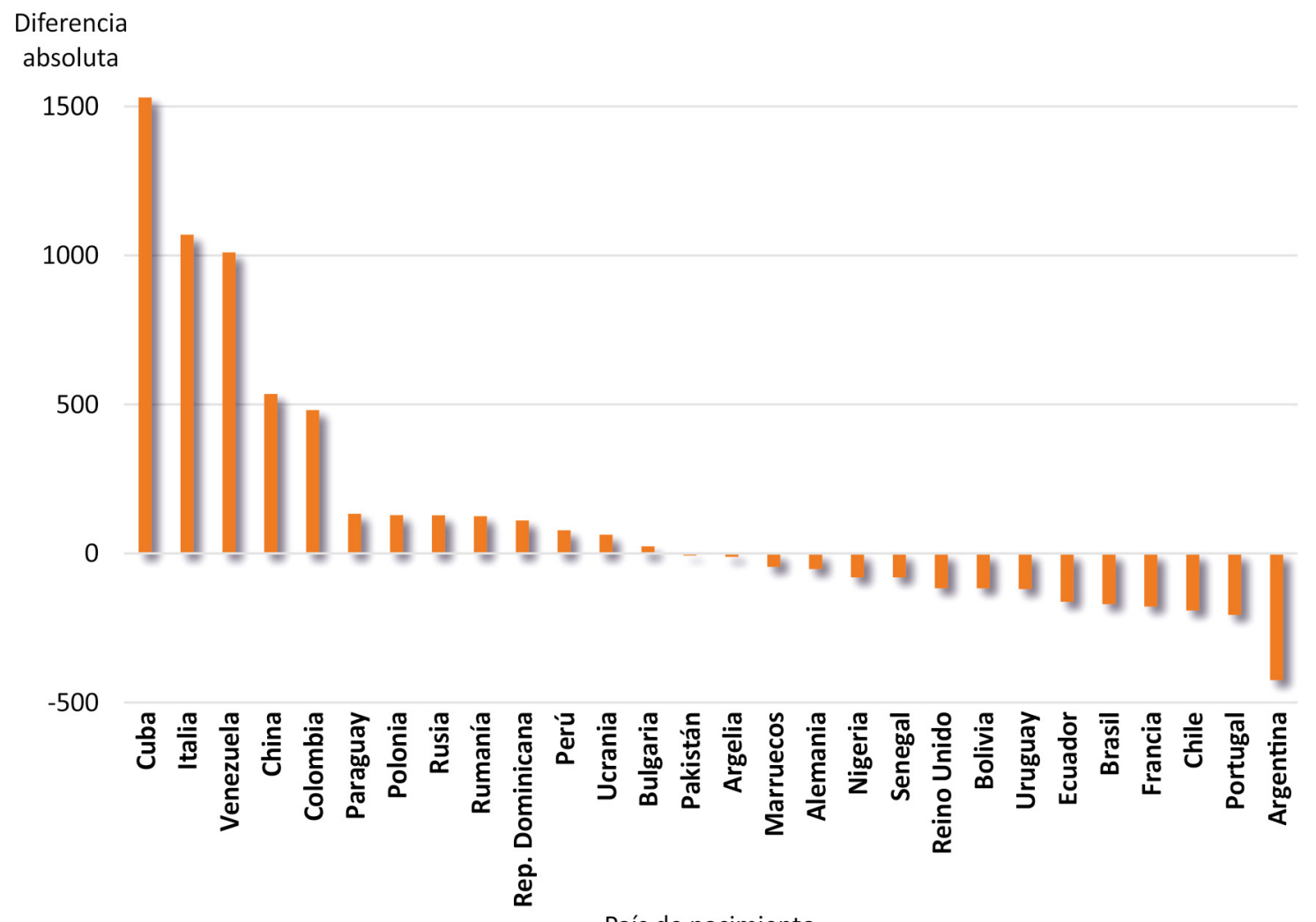

País de nacimiento

Fuente: INE, Padrón Continuo de Población. Elaboración propia.

superaban, en muchos casos, el $20 \%$ en las secciones de estos barrios. Junto a esta zona, las cifras eran también especialmente elevadas en el resto de los ámbitos centrales de la ciudad, entre los barrios Ciudad Jardín y Vegueta, especialmente en algunas zonas de Lugo y Canalejas. Fuera de estas áreas centrales, la presencia de nacidos en el extranjero era relevante en Ciudad Alta, la zona de crecimiento urbano construida desde los años cuarenta del siglo pasado, comprendida entre los barrancos de Tamaraceite y Guiniguada. En este ámbito, este colectivo destacaba en el entorno de la Avenida de Escaleritas y en el barrio de Schamann. El resto del espacio urbano presentaba valores inferiores al $10 \%$. Por tanto, desde el punto de vista urbanístico, esta población mostraba una especial preferencia por barrios centrales o con centralidad secundaria y parecía evitar las zonas que conforman el mapa de las viviendas públicas y autoconstruidas de la ciudad, donde la oferta de vivienda en alquiler es menor.

La distribución intraurbana de la población nacida en el extranjero por país de nacimiento presentaba importantes diferencias en 2018 (figura 7). La mayor parte de los que habían nacido en países de la Unión Europa residían en el distrito $3(44,3 \%)$ y en las secciones del distrito 2, que corresponden al centro de la ciudad (2C), con algunas excepciones como la de los rumanos o portugueses, que preferían también el distrito 4 (Ciudad Alta). Los nacidos en países africanos, americanos y de la Europa no comunitaria residían en los distritos 3 y 4 , llegando a ser mucho más numerosos los nacidos en el continente americano en este último distrito (33\%). En este grupo, las nacidas en Paraguay, Perú, Ecuador y Bolivia, que residían en el centro de la ciudad (2C), alcanzaban un valor elevado, algo que se relaciona con la importancia del servicio doméstico y cuidado de niños y personas mayores por parte de este colectivo (Domínguez-Mujica, Parreño-Castellano y Armengol Martín, 2020; Domínguez-Mujica y Parreño-Castellano, 2021). Por último, los nacidos en Asia, aunque más abundantes en el distrito 3 , también residían en gran número en los distritos $2 \mathrm{C}$ y 4.

Estas diferencias en la distribución en función del país de nacimiento nos indican una cierta "especialización" según país de nacimiento y distrito. En función de 
los coeficientes de localización, el distrito 3 se caracteriza por una sobre-presencia de nacidos en los países de la Europa Comunitaria, de África y Asia, en términos generales. En el centro de la ciudad (2C) a los de origen comunitario y asiático se suman las empleadas latinoamericanas del servicio doméstico y del cuidado de personas. En el distrito 4, en cambio, los de origen americano, nigeriano, rumano y ucraniano estaban claramente sobrerrepresentados. Los de países del Cono Sur, Venezuela, Cuba, República Dominicana, Marruecos y Europa no comunitaria mostraban una sobre-presencia en el distrito 5, el que concentra la mayor parte del crecimiento reciente de la ciudad. En las secciones de menor renta del distrito 1 y en la zona del barranco de Mata (2M) los de origen americano, africano, portugués, rumano y búlgaro manifiestan una clara sobrerrepresentación, mientras que, en las secciones de mayor renta de este distrito, los de origen británico, francés y ruso predominan, en términos relativos.

Con todo esto queremos decir que las diferencias de renta per cápita, ocupación, motivación y consolidación del flujo migratorio por país de origen condicionan la mayor o menor presencia de algunos grupos nacionales en determinadas zonas, tanto en términos absolutos como relativos, no teniendo por qué coincidir siempre, en ambos casos.

Pero llama la atención la importancia cuantitativa que alcanzaba el distrito 3 , aun siendo un espacio donde los precios de las viviendas no eran asequibles para una buena parte de los inmigrantes. Esto se explica por el hecho de que, en esta zona, el mercado de la vivienda en alquiler es, por un lado, más amplio y dinámico y, por otro, porque éste se encuentra segmentado en diferentes niveles de renta, por la existencia de un amplio stock de antiguos apartamentos turísticos, convertidos al uso residencial a partir de los ochenta (Domínguez-Mujica, González-Pérez y Parreño-Castellano, 2008, Domínguez-Mujica, GonzálezPérez, Parreño- Castellano y Sánchez Aguilera, 2021). Estos inmuebles se alquilaban a precios inferiores al promedio de la zona, debido a su estado de conservación o a sus características habitacionales. En consecuencia, esta oferta en alquiler, a la que se sumó otra, de inmuebles envejecidos y devaluados del centro, y de inmuebles en promociones de vivienda de renta libre, construidos entre los sesenta y ochenta, permitió que una buena parte de los migrantes laborales llegados desde finales del siglo pasado pudiera alojarse en ubicaciones con un alto o medio nivel de centralidad en los distritos $2 \mathrm{C}, 3$ y 4 , al mismo tiempo que la llegada de estos grupos movilizaba un mercado de viviendas en alquiler adormecido.

\subsection{Relación entre la población de origen extranjero y desahucio.}

Los datos judiciales sobre desahucio de vivienda en alquiler no proporcionan información sobre el número de personas afectadas (solamente sobre el arrendatario), ni tampoco sobre sus características demográficas y socioeconómicas. Tampoco es posible saber cuántos expedientes afectan a cada tipo y tamaño de hogar, ni a situaciones habitacionales como el subarriendo, ni medir las consecuencias del desahucio en el número de personas sin hogar y, por supuesto, tampoco se puede identificar el país de origen de las personas afectadas.

Dadas estas limitaciones, el análisis geográfico que relaciona la distribución de la población nacida en el extranjero con la de los expedientes de privación de uso, vinculados a la ley de arrendamiento urbano, puede ser una herramienta para solventar las carencias informativas de los registros judiciales. Ambas distribuciones territoriales parecen presentar cierta superposición espacial, a tenor de lo que se puede apreciar en las figuras 5 y 7 , lo que nos llevó a medir el nivel de asociación o correlación de ambas variables.

Si analizamos sus histogramas de frecuencias a escala de sección censal, se aprecia cierta asimetría positiva, con la presencia de un número elevado de valores atípicos leves y extremos. Ambas razones, asimetría y presencia de valores atípicos, hacen que no podamos demostrar la normalidad de las variables con el test de Kolmogorov-Smirnov. Por ello, utilizamos el coeficiente de correlación no paramétrico de Spearman, con la finalidad de valorar el nivel de asociación de la distribución de la población nacida en el extranjero empadronada el uno de enero de 2018 , por una parte, y del número de desahucios con resultado positivo de inmuebles en arrendamiento, por otra. La correlación obtenida es 0,59 , con una significancia bilateral de 0,01. Es decir, allí donde el número de personas nacidas en el extranjero es mayor, también es mayor el número de desahucios registrados en el periodo analizado, con un grado de asociación elevado.

Este nivel de asociación tiene su correlato en tres hechos que conviene destacar. En primer lugar, el alquiler a precio de mercado es una forma de acceso a la vivienda más frecuente entre la población extranjera. Los datos de tenencia, recogidos en el Censo de Población y Vivienda de 2011, para el municipio, así lo confirman. En ese año, el $17 \%$ de los hogares vivía en alquiler. Pues bien, un tercio de estas viviendas era ocupado por hogares en los que al menos una persona era de nacionalidad extranjera, lo que suponía que 
FIGURA 7

PORCENTAJE DE EMPADRONADOS NACIDOS EN EL EXTRANJERO RESPECTO A LA POBLACIÓN DE LAS SECCIONES CENSALES DE LAS PALMAS DE GRAN CANARIA (2018)

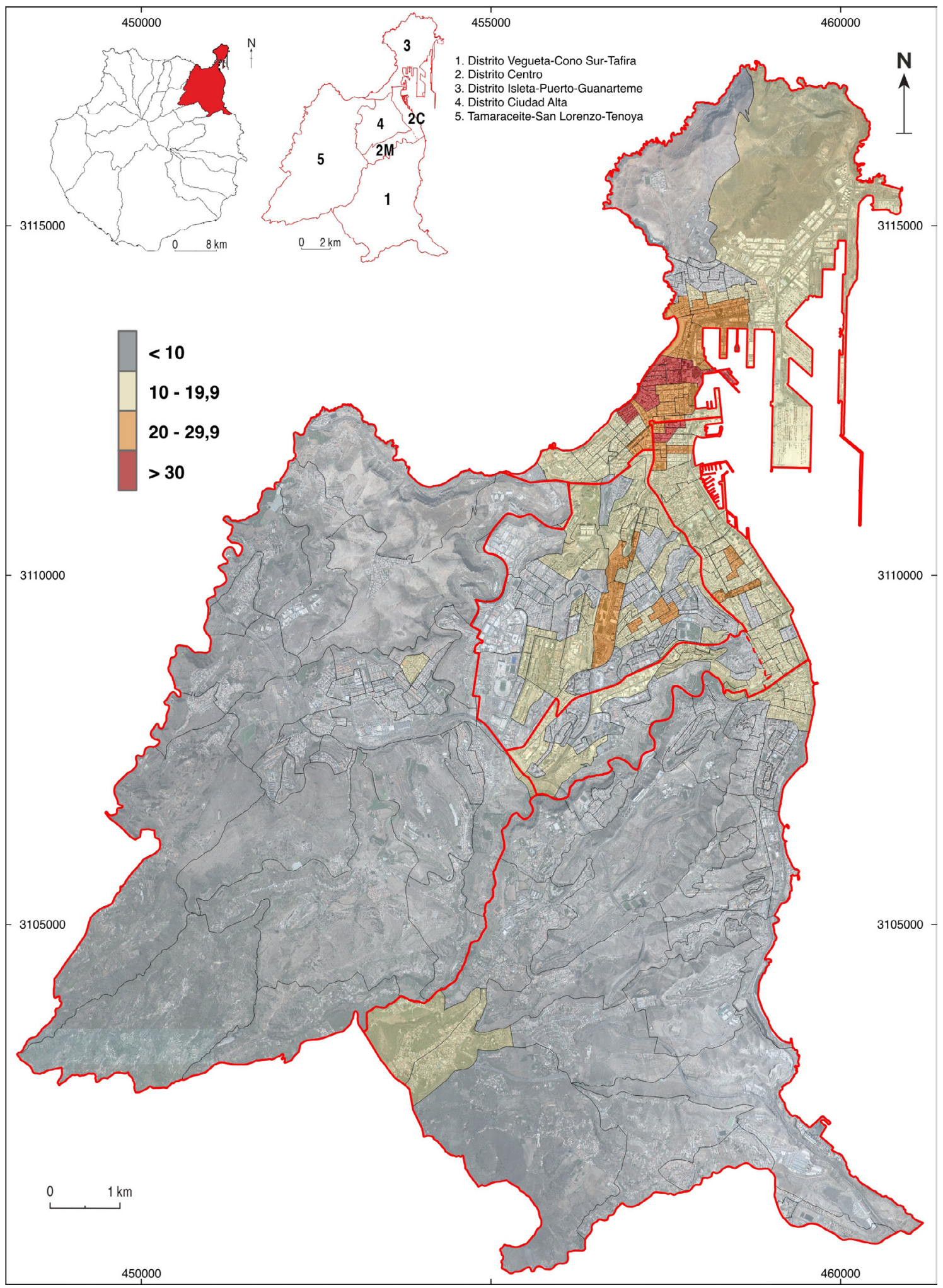

Fuente: INE, Padrón Continuo de Población. Elaboración propia. 
el $52 \%$ de estos hogares viviese en alquiler, frente al $12 \%$ de los que estaban formados en su totalidad por personas de nacionalidad española. Por tanto, alquiler e inmigración son dos fenómenos interrelacionados en Las Palmas de Gran Canaria.

Esta relación entre inmigración y alquiler se ha mantenido a lo largo de todo el periodo, como se puede apreciar en la Encuesta de Condiciones de Vida. En el periodo 2004-19, como promedio en España, el 68,2\% de los hogares extranjeros no comunitarios vivía en alquiler a precio de mercado y el $4,9 \%$ con un alquiler con un precio inferior al mismo. El alquiler a precio de mercado era, como promedio, el 52,5\% entre los comunitarios.

En segundo lugar, la población de origen extranjero fue especialmente afectada por la crisis económica iniciada en 2008. Como la mayoría de los migrantes laborales asentados en la ciudad se ocupaban en sectores productivos en los que se notó sobremanera el impacto de la crisis económica e inmobiliaria (la construcción y otras actividades directamente relacionadas con ella, el comercio al por menor y la restauración), la bajada de ingresos o el desempleo que les ocasionó supuso que muchos inmigrantes tuvieran dificultades para poder hacer frente al pago de sus alquileres. Entre 2002 y 2007, las diferencias en las tasas de paro trimestrales entre españoles y extranjeros no comunitarios en Canarias habían sido reducidas, con un promedio en torno al $1 \%$, según la Encuesta de Población Activa. Las cifras comenzaron a subir desde 2008 al mismo tiempo que lo hacían las tasas de desempleo, de tal modo que en el periodo que se extendió hasta 2013, la diferencia promedio fue de ocho puntos, registrándose tasas de desempleo superiores al $40 \%$ entre los extranjeros no comunitarios en algunos trimestres. Esto es coherente con el hecho de que una buena parte de los inmigrantes se ocupara en este periodo en el denominado mercado secundario, caracterizado por actividades intensivas en mano de obra, baja productividad y reducidos salarios, con alta temporalidad y escasas posibilidades de promoción (Caparrós Ruiz y Navarro Gómez, 2009)

Como agravante de todo esto, la vulnerabilidad derivada de la condición de extranjero no comunitario hizo que muchos tuvieran una menor capacidad de respuesta (Díaz Hernández, Domínguez Mujica y Parreño-Castellano, 2017). La falta de ahorro y de apoyo de redes familiares y la imposibilidad de acudir a subsidios públicos incidió en una mayor vulnerabilidad (Valero-Matas, Coca y Valero-Oteo, 2014). En este sentido, conviene recordar que el colectivo de extranjeros no comunitario sufre una situación de exclusión residencial por discriminación directa o indirecta de manera "estructural", como han afirmado algunos estudios (Amnistía Internacional España, 2017; Gutiérrez Sanz y Jarabo Torrijos, 2013; Martínez Goytre, 2020).

Y, en tercer lugar, la situación que ha experimentado el mercado inmobiliario desde 2014, con crecimiento de los precios de los alquileres muy por encima del incremento de los ingresos de los hogares en especial en algunas zonas de la ciudad. Así, basta ver la evolución reciente de los precios en Santa CatalinaLas Canteras para que se aprecie la tendencia inflacionista que ha situado a buena parte del distrito en el listado de áreas con alquileres medios más elevados de España, ya que, entre 2015 y 2018, el precio medio del alquiler creció más de un $30 \%$ en esta zona (figura 8). Al mismo tiempo, la ciudad ha experimentado un crecimiento espectacular de la vivienda vacacional, de tal manera que, en 2018, se registraban 7.147 camas, distribuidas en 1.891 viviendas, lo que suponía una cifra próxima al $60 \%$ de las plazas en alojamiento reglado en aquel año, según el Registro de Vivienda Vacacional del Gobierno de Canarias. La mayoría de estos establecimientos vacacionales se pusieron en explotación en el distrito 3 (Santa Catalina-Las Canteras) (Domínguez-Mujica, Parreño-Castellano y Moreno-Medina, 2020).

Si tenemos presente que la recuperación económica se ha hecho desde 2014 a costa de la precarización de la mano de obra asalariada y de la bajada de las retribuciones (Gabarre de Sus, 2019), la población en régimen de alquiler ha empezado a tener dificultades crecientes, en términos generales, para pagar sus rentas en los barrios de la ciudad en los que se producían incrementos de precio. Esto ha afectado especialmente a los ciudadanos de origen foráneo no comunitario ya que entre ellos predominan los que tienen empleos mal retribuidos, baja cualificación y escasa estabilidad laboral (Iglesias, Rua y Ares, 2020). En este sentido, la Encuesta de Condiciones de Vida de 2019 ha puesto de manifiesto, en este sentido, que la renta media de la población extranjera en alquiler es, como promedio, la mitad de la que tienen los hogares españoles en viviendas arrendadas.

Por tanto, la fuerte relación territorial entre desahucio por impago de renta y población de origen extranjero (en especial con la no comunitaria) se fundamenta en la importancia del alquiler a precio de mercado en este colectivo, en el estrés que supuso para los extranjeros el pago de las rentas en el escenario de fuerte desempleo originado por la crisis económica de 
Euros $/ m^{2}$

13

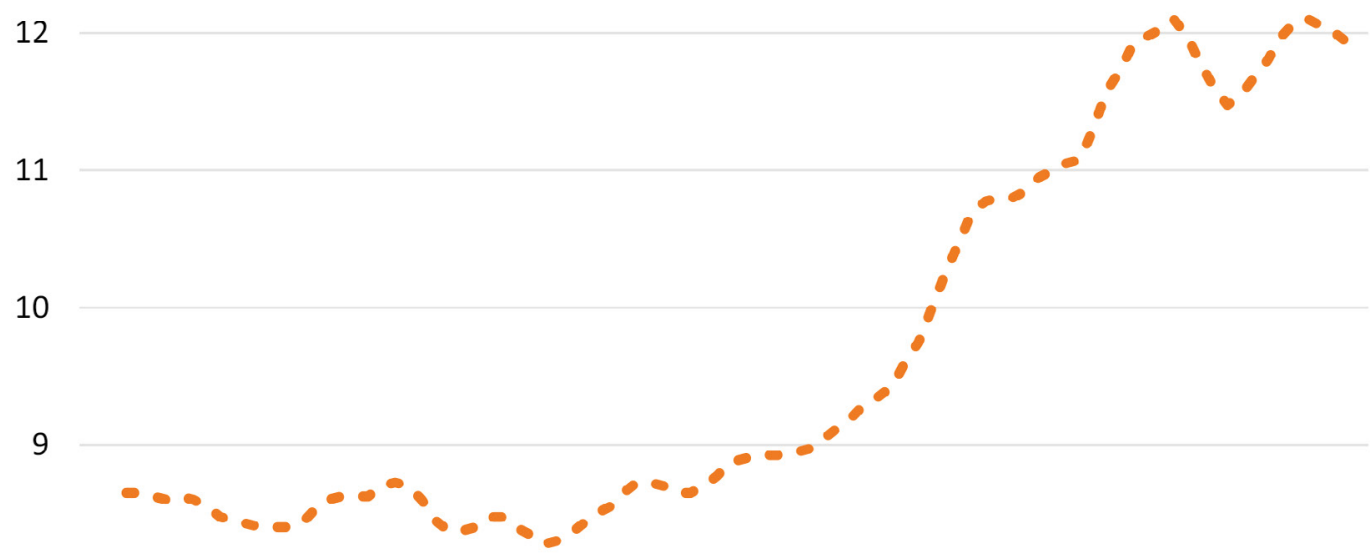

8

7

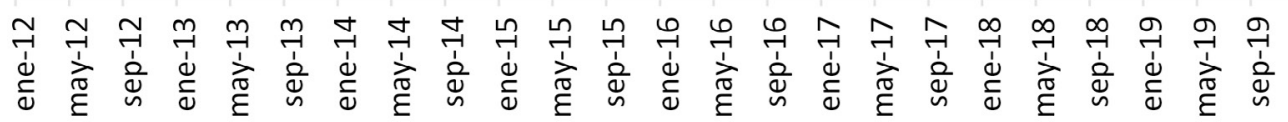

Mes-Año

Fuente: El Idealista.com. Elaboración propia. Representación a partir del cálculo de medias móviles con cuatro periodos trimestrales.

2008 y en el elevado incremento de las dificultades de pago desde 2014 motivada por un crecimiento de los precios superior al de los ingresos.

\subsection{Desplazamiento y sustitución. Hacia una nueva estratificación territorial de la población de origen extranjero.}

Hemos visto que el fenómeno del desahucio de la vivienda en alquiler adquiere especial importancia en determinadas zonas centrales de la ciudad. Esas zonas son, por otro lado, las que concentran mayor población nacida en el extranjero y, por consiguiente, existe una relación entre la pérdida de vivienda en alquiler y la presencia de población nacida en el extranjero. Este tipo de relación se da en un contexto de crisis económica, en un primer término, y de crecimiento especulativo de los precios de los alquileres, después. Ambos procesos han afectado al colectivo de extranjeros en cuanto a que éstos han mostrado una mayor vulnerabilidad en ambas coyunturas.
Podemos plantearnos en este momento si las pautas de distribución intraurbana de la población de origen extranjero han cambiado entre 2009 y 2018. Si esto fuera así, podríamos interpretar que la evolución del mercado de la vivienda y el fenómeno del desahucio pueden estar originando dinámicas de desplazamiento territorial.

Para analizar este fenómeno, podemos partir del estudio de la dispersión territorial de la población de origen extranjero. Así, se aprecia que la tendencia general entre ambas fechas es la de un incremento en la homogeneidad en el conjunto de la ciudad, pues el Índice de Variación desciende del 109,8 al 94,6\% entre 2009 y 2018, coincidiendo con un incremento en 4.201 personas. Esto puede ser debido a que en las secciones con menos población de origen extranjero se incrementa en mayor medida este colectivo o a que las que tenían más población tienden a perder a una parte de aquellos residentes. En Las Palmas de Gran 
Canaria ambos procesos han concurrido. Como podemos ver en la tabla 1 , las tasas de crecimiento en los distritos centrales de la ciudad ( 2 C y 3 ), lo que tenían un mayor índice de extranjería, son las más reducidas en el periodo considerado, al mismo tiempo que las tasas más elevadas se registran en los distritos más periféricos, el 1 y el 5, justamente los que tenían un menor índice. Por tanto, ambos procesos explican la homogenización de la distribución y parecen manifestar la existencia de una dinámica de desplazamiento, si no directo, al menos indirecto (Marcuse, 1985).

Junto a esto, en el distrito 3, el que concentra un contingente mayor, se detecta un descenso de los residentes nacidos en el extranjero en cifras absolutas a partir de 2014. La pérdida de población nacida en el extranjero es tan elevada en esta zona que podemos colegir que el mercado de la vivienda en alquiler está favoreciendo el desplazamiento de la población analizada hacia fuera del municipio o hacia otros distritos del mismo, a la vez que desincentiva la llegada de nuevos inmigrantes. Además, la expulsión de personas de origen extranjero en este distrito se produce al mismo tiempo que en él se concentran los desahucios por impago de renta de la ciudad.

El análisis por país de nacimiento permite matizar el proceso de desplazamiento que se ha activado con el inicio de la recuperación económica, pudiéndose reinterpretar también como un proceso de sustitución. En

TABLA 1

POBLACIÓN NACIDA EN EL EXTRANJERO EN LAS PALMAS DE GRAN CANARIA POR DISTRITOS

\begin{tabular}{|l|c|c|c|c|c|c|c|c|c|}
\hline & \multicolumn{3}{|c|}{ Valores absolutos } & \multicolumn{3}{c|}{ Diferencia } & \multicolumn{3}{c|}{ Tasa de Crecimiento } \\
\hline & 2009 & 2014 & 2018 & $2014-09$ & $2018-14$ & $2018-09$ & $2014-09$ & $2018-14$ & $2018-09$ \\
\hline Distrito 1 & 3.293 & 3.670 & 4.072 & 377 & 402 & 779 & 11,4 & 11,0 & 19,1 \\
Distrito 2M & 2.403 & 2.465 & 2.669 & 62 & 204 & 266 & 2,6 & 8,3 & 10,0 \\
Distrito 2C & 8.882 & 8623 & 8.982 & -259 & 359 & 100 & $-2,9$ & 4,2 \\
Distrito 3 & 14.144 & 15.676 & 14.796 & 1.532 & -880 & 652 & 10,8 & $-5,6$ & 4,1 \\
Distrito 4 & 10.907 & 11.865 & 12.487 & 958 & 622 & 1.580 & 8,8 & 5,2 & 12,7 \\
Distrito 5 & 2.327 & 2.997 & 3.114 & 670 & 117 & 787 & 28,8 & 3,9 & 25,3 \\
\hline
\end{tabular}

Fuente: INE, Padrón Continuo de Población. Elaboración propia. El distrito 2 se ha subdividido en dos zonas: 2C, que incluye las secciones del centro de la ciudad y $2 \mathrm{M}$, que comprende las secciones en el entorno del barranco de Mata.

TABLA 2

POBLACIÓN NACIDA EN EL EXTRANJERO POR PAÍS DE NACIMIENTO Y DISTRITO EN LAS PALMAS DE GRAN CANARIA (2014-18)

\begin{tabular}{|c|c|c|c|c|c|c|c|}
\hline & Distrito 1 & Distrito $2 \mathrm{M}$ & Distrito $2 \mathrm{C}$ & Distrito 3 & Distrito 4 & Distrito 5 & Municipio \\
\hline Unión Europea & 7,5 & $-6,1$ & $-0,6$ & $-6,7$ & $-10,1$ & $-10,6$ & $-4,73$ \\
\hline Alemania & $-18,5$ & 0,0 & $-12,2$ & $-12,0$ & $-31,3$ & $-14,3$ & $-15,47$ \\
\hline Italia & 45,6 & 61,1 & 30,1 & 31,8 & 30,7 & 25,0 & 32,49 \\
\hline Europa No Comunitaria & 36,8 & 25,0 & 5,6 & $-11,3$ & 3,9 & 36,5 & 3,70 \\
\hline África & 1,7 & $-3,7$ & 1,3 & $-8,9$ & 1,4 & $-3,4$ & $-3,55$ \\
\hline Marruecos & 8,2 & $-4,0$ & $-1,9$ & $-12,0$ & $-1,1$ & $-2,6$ & $-5,56$ \\
\hline América & 15,3 & 12,7 & 4,1 & $-3,0$ & 10,4 & 8,5 & 6,12 \\
\hline Argentina & $-2,0$ & 0,7 & $-5,6$ & $-15,2$ & $-6,7$ & $-12,2$ & $-8,64$ \\
\hline Colombia & 19,5 & 4,4 & $-5,0$ & $-9,6$ & 9,5 & 7,6 & 2,18 \\
\hline Cuba & 12,6 & 12,0 & 9,8 & 2,9 & 12,9 & 0,8 & 8,20 \\
\hline Ecuador & $-3,9$ & $-7,3$ & $-22,5$ & $-25,6$ & 1,0 & 32,6 & $-10,76$ \\
\hline Venezuela & 36,0 & 49,8 & 24,9 & 28,7 & 24,0 & 20,9 & 27,47 \\
\hline Asia & 0,4 & 22,8 & 15,3 & $-5,3$ & $-2,3$ & 0,6 & 1,09 \\
\hline China & $-9,7$ & 11,8 & 25,8 & $-4,6$ & 0,0 & 3,6 & 4,54 \\
\hline
\end{tabular}

Fuente: INE, Padrón Continuo de Población. Elaboración propia. El distrito 2 se ha subdividido en dos zonas: 2C, que incluye las secciones del centro de la ciudad y $2 \mathrm{M}$, que comprende las secciones en el entorno del barranco de Mata. 
FIGURA 9

SALDOS DE NACIDOS EN EL EXTRANJERO POR PAIS DE NACIMIENTO EN LAS PALMAS DE GRAN CANARIA ENTRE 2012 Y 2019

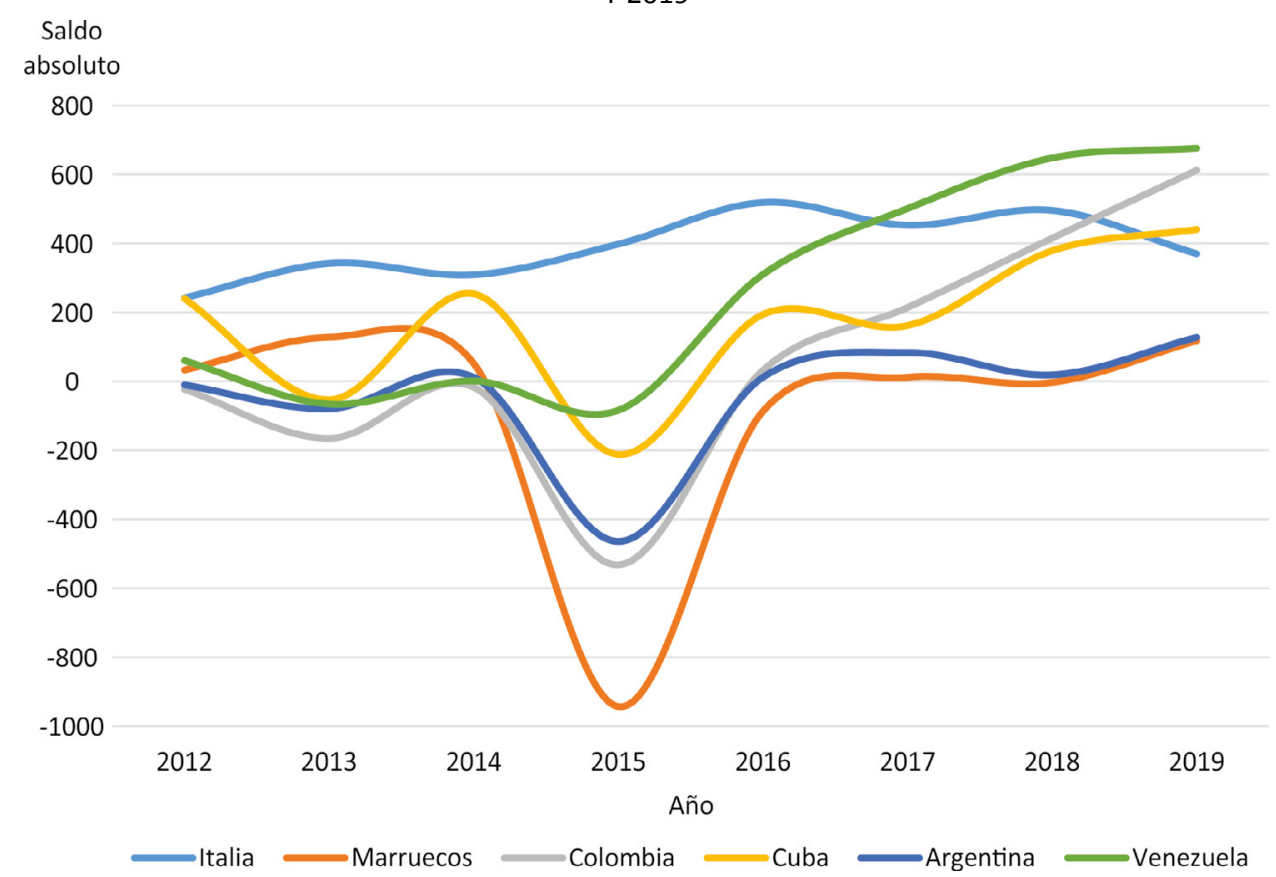

Fuente: INE, Estadística de Variaciones Residenciales. Elaboración propia.

este sentido, detectamos que, en función de las tasas de crecimiento registradas entre 2014 y 2018 por distrito, para grandes grupos nacionales y para aquellos países con más de un millar de empadronados en el primer año, se aprecia un decrecimiento en el número de los nacidos en la Unión Europea y África, con una especial incidencia para los originarios de Alemania y Marruecos. Esta misma tendencia se ha registrado entre algunos oriundos de países latinoamericanos como Argentina o Ecuador. Por el contrario, se ha producido un elevado crecimiento de los nacidos en Italia, Venezuela y Cuba (tabla 2).

En concreto, en el distrito 3, las tasas de crecimiento son negativas para todos los orígenes considerados, salvo para los nacidos en Italia, Venezuela y Cuba, sin que estos estos crecimientos hayan conseguido paliar el proceso generalizado de abandono que se registra en esta zona entre la población extranjera. En el centro de la ciudad (distrito 2C) la tendencia es parecida, pero se ve algo más atenuada por el mayor incremento de nacidos en China y Cuba, que se suma a los procedentes de Italia y Venezuela. En definitiva, lo que se ha producido es un proceso de sustitución de la población de origen extranjero por país de nacimiento, de tal manera que los flujos inmigratorios recientes procedentes sobre todo de Italia y Venezuela han venido a compensar parcialmente la pérdida de población de otros orígenes.

Esta sustitución de grupos por país de nacimiento se evidencia en los saldos municipales de las variaciones residenciales. Como se puede apreciar en la figura 9, mientras que los nacidos en Argentina o Marruecos han registrado en el periodo representado saldos negativos o cercanos a 0, desde 2015 los saldos de nacidos en Cuba, Colombia y Venezuela se han incrementado sustancialmente. El aumento de los saldos de los nacidos en Italia se remonta incluso a años anteriores.

Por tanto, lo que está ocurriendo es que, en las zonas que experimentan un mayor crecimiento de los precios de arrendamiento y en las que se concentran los desahucios de vivienda en alquiler, se está produciendo una pérdida absoluta o relativa de población de origen extranjero (especialmente de países no comunitarios), que parece trasladarse a otras zonas de la ciudad, o fuera del municipio, al mismo tiempo que se adivina un proceso de sustitución de población inmigrante por país de procedencia.

Es complejo aventurar si las repercusiones de la actual crisis económica provocada por la COVID-19 revertirá la correlación entre desahucio y extranjería en la ciudad de Las Palmas de Gran Canaria o si in- 
tensificará aún más su relación, o si estos procesos de desplazamiento y sustitución, que parecen relacionados espacialmente, se harán más evidentes o se revertirán. La paralización temporal de los expedientes de impago como medida anticrisis, el escenario complejo que tiene el mercado de la vivienda de uso turístico, la falta de perspectivas sobre la movilidad internacional y la ausencia de consenso sobre la duración y profundidad de la crisis no permiten aportar estimaciones certeras. Cabe pensar, no obstante, que la vulnerabilidad que conlleva la condición de extranjero y su menor capacidad de resiliencia ante situaciones críticas hagan perdurar las pautas que hemos venido describiendo.

\section{CONCLUSIONES}

Tras la irrupción de la crisis económica de 2008 y sucesivos, la mayor parte de las investigaciones realizadas en España en relación con la vivienda y la vulnerabilidad urbana a ella asociada, prestaron una gran atención a los procedimientos de ejecución hipotecaria, a consecuencia de la expansión inmobiliaria del tránsito de los siglos XX al XXI, la llamada etapa de la burbuja inmobiliaria, y de la subsiguiente fase de contracción y recesión económicas, la de su estallido. Por tanto, es muy numerosa la bibliografía referida a los procesos de financiarización de la vivienda y de posterior desposesión, así como a sus efectos en el bienestar colectivo. Sin embargo, son menos frecuentes los trabajos referidos a los desahucios por impago de alquileres, otra de las manifestaciones de la crisis $y$, tal vez, la de mayor significación en términos de vulnerabilidad urbana.

Por otra parte, con respecto a una etapa económica reciente, la de la llamada poscrisis, el mercado inmobiliario se ha visto sujeto a tales transformaciones que comienzan a aparecer numerosos trabajos de investigación en relación con su reestructuración, un proceso en el que han tenido una importante participación la SAREB y el diseño de una política de reposesión, en la que ha jugado un destacado papel la inversión internacional y las estrategias de ciertos operadores, los llamados fondos buitres. Las consecuencias de estos nuevos actores en distintas ciudades españolas, favoreciendo procesos de turistificación, entre otros, han centrado el foco de atención de las investigaciones más recientes.

A estas dos grandes temáticas del ámbito de la geografía urbana, social y económica, anteriormente descritas, hemos de sumar los estudios geográficos de carácter demográfico y sociourbano acerca de la vulnerabilidad y pautas de exclusión o segregación residencial de la población extranjera en España. La intensidad de la inmigración foránea en el cambio de siglo, coincidente con la etapa de expansión económica, y la mayor incidencia de la crisis en el mercado de trabajo de la población extranjera en años posteriores, han sido foco de atención de innumerables análisis. Sin embargo, poco se ha escrito aún acerca de la recuperación -aunque más lenta- de la inmigración en los años de poscrisis (Parreño-Castellano, MorenoMedina, Domínguez-Mujica y Santana Rivero, 2021) y acerca de las características de los flujos según procedencias y condiciones de vida en esta etapa de reestructuración.

El estudio desarrollado trata de aunar estas tres perspectivas de análisis en el caso de Las Palmas de Gran Canaria, una ciudad insular en la que tiene un importante peso su especialización turística. Concretamente, centramos nuestra atención en la relación intrínseca entre mercado de la vivienda e inmigración pues, desde una perspectiva sociourbana, se pone de manifiesto la vulnerabilidad de la población extranjera en el mercado de la vivienda en alquiler y su desplazamiento o expulsión territorial, en situaciones de reposesión y de elitización residencial.

En concreto, hemos visto, en primer lugar, que en el partido judicial de Las Palmas de Gran Canaria entre 2009 y 2017 se ejecutó de manera positiva un número considerable de expedientes de desahucio fundamentalmente por impago del alquiler. El número de expedientes fue elevado en los primeros años de la crisis económica iniciada en 2008, estabilizándose entre 2011 y 2014 . Desde este último año, el número de desahucios de viviendas en arrendamiento ha crecido de manera espectacular, alcanzándose valores mayores que los registrados con la crisis económica previa. Por tanto, hemos podido concluir que los lanzamientos no se vinculan tan sólo a la crisis, sino también a la forma en que se reestructura la economía en los últimos años, en la llamada poscrisis.

En segundo lugar, hemos mostrado que los expedientes de desahucio se concentran en áreas centrales y de la primera corona periurbana de la ciudad, destacando las cifras en los barrios situados en el entorno de las playas de Las Canteras y Alcaravaneras y en el puerto de La Luz. Precisamente en estos barrios es en donde también se concentra la residencia de la población extranjera, de tal manera que la distribución de los desahucios y de la población extranjera, especialmente la no comunitaria, presenta un elevado coeficiente de correlación espacial. 
Además, hemos visto que la población extranjera (en especial la no comunitaria) ha optado predominantemente por el alquiler a precio de mercado como forma de acceso a la vivienda, mostró una mayor afección a la crisis económica y está padeciendo un claro proceso de precarización laboral. Por tanto, el análisis geográfico y los indicios socioeconómicos apuntan a que los desahucios de las viviendas en alquiler han afectado especialmente a la población de origen extranjero no comunitario, tanto en el periodo de crisis como en el de la reciente recuperación, como apuntábamos entre las hipótesis.

En tercer lugar, hemos señalado que se está produciendo un crecimiento de los alquileres desde 2014 en casi toda la ciudad. Este hecho está motivando que el esfuerzo de pago y la inseguridad residencial vayan en aumento, en especial en las zonas centrales de la ciudad, en las que además reside un elevado número de extranjeros. Señalábamos que era previsible que se estuviera produciendo un proceso de gentrificación, algo que está aún por analizar en profundidad. Pero lo que si constatábamos es que, en estos barrios, se producía una pérdida en términos absoluto y relativo de población extranjera empadronada, que está siendo desplazada a otros barrios desde 2014.

Por tanto, como apuntábamos entre las premisas de partida, en el reciente periodo de poscrisis, el crecimiento de las rentas de alquiler es tan elevado que está ocasionando la expulsión de la población de origen extranjero más vulnerable. El hecho de que estos barrios sean además los que concentran los lanzamientos por impago de alquileres nos lleva a pensar que existe una relación con el desplazamiento reseñado.

$\mathrm{Y}$, en cuarto lugar, indicábamos que se aprecian diferencias según nacionalidad en lo que respecta a la expulsión de los residentes extranjeros de los barrios en lo que se produce un mayor incremento de los alquileres. Mientras algunas nacionalidades tienden a perder presencia en estas zonas y a ganarla en otras áreas de la periferia urbana, otras, las que acaparan la mayor parte de los flujos de entrada en el municipio, ganan representación en estos barrios con indicios de elitización. Por tanto, concluíamos que el desplazamiento ha llevado parejo la sustitución de unos residentes de origen extranjero por otros, lo que está generando una estratificación de la población extranjera según origen étnico y niveles de renta.

En síntesis, la ciudad de Las Palmas de Gran Canaria es un adecuado observatorio de la estrecha relación que caracterizan los procesos urbanos de desposesión y reposesión, en los momentos de crisis y de poscrisis, y de la relación que guardan con el acceso a la vivienda por parte de segmentos de población vulnerable, en este caso, la población extranjera no comunitaria. De esta forma, el caso de estudio se convierte en un buen ejemplo de las dinámicas propias de las ciudades insulares españolas cuya evolución deriva de la manera en que interviene el modo de producción capitalista a través de la especialización turística y de las desigualdades sociales inherentes a su puesta en acción.

\section{RECONOCIMIENTOS}

Este trabajo presenta resultados del Proyecto $I+D+i$ "Vivienda y Movilidad internacional en las ciudades de Canarias. La aparición de nuevas formas de desigualdad urbana" (RTI2018-093296-B-C21), financiado por el Ministerio de Ciencia, Innovación y Universidades; la Agencia Estatal de Investigación y el Fondo Europeo de Desarrollo Regional.

\section{REFERENCIAS}

Amnistía Internacional España (2017). La crisis de la vivienda no ha terminado. Recuperado de https:// www.es.amnesty.org/fileadmin/user_upload/Inf. Vivienda_FIN2.pdf.

Ardura Urquiaga, A., Lorente Riverola, I. y Sorando, D. (2021). Vivir en la incertidumbre: burbuja de alquiler y olas de gentrificación entre crisis en Madrid. Revista INVI, 36(101), 56-82. doi:10.4067/ S0718-83582021000100056

Brossat, I. (2019). Airbnb: la ciudad uberizada. Pamplona, España: KataKrak Liburuak.

Burriel de Orueta, E. L. (2014). El estallido de la burbuja inmobiliaria y sus efectos en el territorio. En J. M. Albertos Puebla y J. L. Sánchez Hernández (Eds.) (2014). Geografía de la crisis económica en España (pp. 101-140). Valencia, España: Servei de Publicacions Universitat de València.

Caparrós Ruiz, A. y Navarro Gómez, M. L. (2009). Contratación indefinida y segregación ocupacional según nacionalidad: Andalucía frente al resto de España. Investigaciones Regionales, 14, 81106. Recuperado de https://www.redalyc.org/ pdf/289/28911696004.pdf

Cocola-Gant, A. (2018). Tourism gentrification. En L. Lees y M. Phillips (Eds.): Handbook of Gentrification Studies (pp. 281-293). Cheltenham and Northampton, United Kingdom: Edward Elgar Publishing. 
Cocola-Gant, A. y Gago, A. (2019). Airbnb, buy to let investment and tourism-driven displacement: A case study in Lisbon. Environment and Planning A: Economy and Space, $0(0), 1-18$. doi: 10.1177/0308518X19869012

Díaz Hernández, R., Domínguez Mújica, J. y ParreñoCastellano, J. M. (2017). Vulnerabilidad urbana y segregación residencial de la población extranjera no comunitaria en las ciudades más populosas de Canarias. En XXII Coloquio de Historia Canario Americana, 157, 1-17. Las Palmas de Gran Canaria, España: Cabildo Insular de Gran Canaria. Recuperado de http://coloquioscanariasamerica.casadecolon.com/index.php/CHCA/article/ view/10095

Díaz-Rodríguez, M. C., García-Herrera, L. M., GarcíaHernández, J. S., Armas-Díaz, A. y Ginés de la Nuez, C. (2018). Acumulación por desposesión en Santa Cruz de Tenerife (Canarias-España): los desahucios de inquilinos. En La Península Ibérica en el Mundo: problemas y desafíos para una intervención activa de la geografía (pp.51-58). Lisboa, Portugal: Centro de Estudios Geográficos da Universidade de Lisboa.

Domínguez-Mujica, J. (2021). The Urban Mirror of the Socioeconomic Transformations in Spain. Urban Science, 5(1), 13, 1-17. doi: 10.3390/urbansci5010013

Domínguez-Mujica, J., González-Pérez, J. M. y Parreño-Castellano, J. M. (2008). Transformaciones recientes en barrios turísticos maduros. Los casos de Palma de Mallorca y Las Palmas de Gran Canaria, España. Scripta Nova. Revista Electrónica de Geografía y Ciencias Sociales, 12, 270 (93). Recuperado de https://www.raco.cat/index.php/ ScriptaNova/article/view/115766

Domínguez-Mujica, J., González-Pérez, J.M., ParreñoCastellano, J. M. y Sánchez Aguilera, D. (2021). Gentrification on the Move. New Dynamics in Spanish Mature Urban-Tourist Neighbourhoods, Urban Science, 5(1), 33, 2-18. doi: 10.3390/urbansci5010033.

Domínguez-Mujica, J.; López de Lera, D.; OrtegaRivera, E. y Pérez-Caramés, A. (2020). El sistema migratorio de Latinoamérica-España. Cuadernos Geográficos, 59(3), 37-57. doi: 10.30827/cuadgeo.v59i3.9223

Domínguez Mujica, J., y Parreño Castellano, J. M. (2021). A gender approach to housing loss in
Spain: the case of Las Palmas de Gran Canaria. Geografie-Sbornik CGS, 126(2), 123-147. doi: 10.37040/geografie2021126020123.

Domínguez-Mujica, J., Parreño-Castellano, J. M. y Armengol Martín, M. (2020). Género y desposesión inmobiliaria en Las Palmas de Gran Canaria. En J. Farinós et al. (Ed.), Desafíos y oportunidades de un mundo en transición. Una interpretación desde la geografía (pp. 637-646). Valencia, España: Publicacions de la Universitat de València.

Domínguez-Mujica, J., Parreño-Castellano, J. M. y Moreno-Medina, C. (2020). Vacation Rentals, Tourism, and International Migration: Gentrification in Las Palmas de Gran Canaria (Spain) From a Diachronic Perspective. En C. Ribeiro de Almeida, A. Quintano, M. Simancas, R. Huete y Z. Breda (Eds.), Handbook of Research on the Impacts, Challenges, and Policy Responses to Overtourism. (pp. 237-260). IGI Global. doi: 10.4018/978-17998-2224-0.ch013

Fernández-Cuesta del Río, A. (2015). La burbuja inmobiliaria: causa o efecto de la crisis: repercusión del estallido de la burbuja inmobiliaria sobre la crisis económica. Documento de trabajo. Madrid, Universidad Pontificia de Comillas. Recuperado de https://repositorio.comillas.edu/jspui/bitstream/11531/4637/1/TFG001338.pdf

Gabarre de Sus, M. (2019). Tocar fondo. La mano invisible detrás de la subida del alquiler. Madrid, España: Traficante de Sueños. Recuperado de https://www.traficantes.net/sites/default/files/ pdfs/LEM10_fondos_web.pdf

García-Hernández, J. S., Armas-Díaz, A. y Díaz-Rodríguez, M. C. (2020). Home dispossession and touristification in Santa Cruz de Tenerife (Canary Islands-Spain): tenant evictions in the neighborhood of El Toscal. Boletín de la Asociación de Geógrafos Españoles, 87, 1-38. doi: 10.21138/ bage. 2982

García-Lamarca, M. (2020): Real estate crisis resolution regimes and residential REITs: emerging socio-spatial impacts in Barcelona, Housing Studies, 1-20. doi: 10.1080/02673037.2020.1769034

García Montalvo, J. (2015) Cleaning up the Spanish financial sector's real estate risk exposure: Situation and outlook, SEFO - Spanish Economic and Financial Outlook, 5 (4), 29-45. Recuperado de https://www.funcas.es/wp-content/uploads/Migracion/Articulos/FUNCAS_SEFO/021art04.pdf 
Gil-Alonso, F. y Vidal-Coso, E. (2015). Inmigrantes extranjeros en el mercado de trabajo español: ¿más resilientes o más vulnerables al impacto de la crisis? Migraciones. Publicación del Instituto Universitario de Estudios sobre Migraciones, (37), 97123. doi: 10.14422/mig.i37.y2015.005

González, L. y Ortega, F. (2013). Immigration and housing booms: Evidence from Spain. Journal of Regional Science, 53(1), 37-59. doi: 10.1111/ jors.12010

González Pillado, E. (2012). El juicio monitorio en España tras las últimas reformas procesales. Revista de Estudios de la Justicia, (17), 53-81. doi: 10.5354/0718-4735.2013.29520

Gotham, K. F. (2005). Tourism gentrification: The case of New Orleans' vieux carre (French Quarter). Urban studies, 42(7), 1099-1121. doi: 10.1080/00420980500120881

Gutiérrez Sanz, E. y Jarabo Torrijos, A. (2013). Informe 2013 sobre discriminación en la vivienda hacia personas inmigrantes. Madrid, España: Provivienda. Recuperado de http://nadiesinfuturo.org/ IMG/pdf/Informe_Provivienda_2013.pdf

Iglesias, J., Rua, A. y Ares, A. (2020). Un arraigo sobre el alambre la integración social de la población de origen inmigrante en España. Madrid, España: Cáritas Española Editores.

Jover, J. y Díaz-Parra, I. (2020). Gentrification, transnational gentrification and touristification in SeviIle, Spain. Urban Studies, 57(15), 3044-3059. doi: 10.1177/0042098019857585.

López-Gay, A., Andújar-Llosa, A. y Salvati, L. (2020). Residential Mobility, Gentrification and Neighborhood Change in Spanish Cities: A Post-Crisis Perspective. Spatial Demography, 8(3), 351-378. doi: 10.1007/s40980-020-00069-0.

López-Gay, A., Cocola-Gant, A. y Russo, A. P. (2021). Urban tourism and population change: Gentrification in the age of mobilities. Population, Space and Place, 27(1), e2380, 1-17. doi: 10.1002/psp.2380

Marcuse, P. (1985). Gentrification, Abandonment, and Displacement: Connections, Causes, and Policy Responses in New York City. Journal of Urban and Contemporary Law, 28, 195-240.

Martínez Goytre, E. (coord.) (2020). ¿Se alquila? Racismo y xenofobia en el mercado del alquiler. Madrid, España: Provivienda. Recuperado de https:// www.provivienda.org/wp-content/uploads/Se-
alquila.-Racismo-y-xenofobia-en-el-mercado-delalquiler.pdf

Medina, R. M., Byrne, K., Brewer, S. y Nicolosi, E. A. (2020). Housing inequalities: Eviction patterns in Salt Lake County, Utah. Cities, 104, 102904, 1-11. doi: 10.1016/j.cities.2020.102804

Méndez Gutiérrez del Valle, R. (2013). Crisis económica, vulnerabilidad urbana y desempleo en España. Ciudad y Territorio, XLV(178), 649-667. Recuperado de https://recyt.fecyt.es/index.php/ CyTET/article/view/76243

Méndez Gutiérrez del Valle, R. (2019). Ciudades en venta. Estrategias financieras y nuevo ciclo inmobiliario en España. Valencia, España: Publicacions de la Universitat de València.

Méndez Gutiérrez del Valle, R. (2021). Financiarización urbana y burbuja del alquiler en España: tendencias y contrastes en perspectiva multiescalar. Documents d'Anàlisi Geogràfica, 1-23. doi: 10.5565/rev/dag.664.

Módenes, J. A. (2017). La inseguridad residencial por problemas económicos en España comparada con el entorno europeo. Papers: revista de sociologia, 102(4), 673-703. doi:10.5565/rev/papers.2416

Módenes, J. A. (2019). El insostenible aumento de la inseguridad residencial en España. Perspectives Demogràfiques, 13, 1-4. doi: 10.46710/ced.pd.esp.13

Mussa, A., Nwaogu, U. G. y Pozo, S. (2017). Immigration and housing: A spatial econometric analysis. Journal of Housing Economics, 35, 13-25. doi: 10.1016/j.jhe.2017.01.002

Nilsson, J. H. (2020). Conceptualizing and contextualizing overtourism: the dynamics of accelerating urban tourism. International Journal of Tourism Cities, 6(4), 657-671. doi: 10.1108/IJTC-08-20190117

Parralejo Sánchez, J. J. y Díaz-Parra, I. (2021). Gentrificación y turistificación en las áreas urbanas centrales de Sevilla y Cádiz. En J.M. Parreño-Castellano y C. Moreno-Medina (Coords.), La reconfiguración capitalista de los espacios urbanos: transformaciones y desigualdades (pp. 293-306). Las Palmas de Gran Canaria, España: Servicio de Publicaciones y Difusión Científica de la Universidad de Las Palmas de Gran Canaria y Asociación Española de Geografía. doi: 10.20420/1642.2021.383.

Parreño-Castellano, J. M., Domínguez-Mujica, J., Armengol Martín, M. T., Boldú Hernández, J. y Pérez 
García, T. (2019). Real estate dispossession and evictions in Spain: a theoretical geographical approach. Boletín de la Asociación de Geografía Española, 80, 2602, 1-25. doi: 10.21138/bage.2602.

Parreño-Castellano, J. M., Domínguez-Mujica, J., Armengol-Martín, M., Pérez-García, T. y Boldú Hernández, J. (2018a). Descapitalización inmobiliaria y desahucio en Las Palmas de Gran Canaria: una aproximación desde fuentes judiciales. En F. Cebrián Abellán (Eds.), Ciudades Medias y Áreas Metropolitanas. De la dispersión a la regeneración (pp. 719-732). Cuenca, España: Ediciones de la Universidad de Castilla-La Mancha.

Parreño-Castellano, J. M., Domínguez-Mujica, J., Armengol-Martín, M., Pérez García, T. y Boldú Hernández, J. (2018b). Foreclosures and evictions in Las Palmas de Gran Canaria during the economic crisis and post-crisis period in Spain. Urban Science, 2(4), 109, 1-15. doi:10.3390/urbansci2040109.

Parreño-Castellano, J. M., Moreno-Medina, C., Domínguez-Mujica, J. y Santana Rivero, C. (2021). Mapping foreign immigration in Spain (1998-2018). Trends and spatial patterns. Journal of Maps, 1-6. doi: 10.1080/17445647.2020.1866700.

Robinson, D. y Steil, J. (2020). Eviction Dynamics in Market-Rate Multifamily Rental Housing. Housing Policy Debate, 31(3-5), 647-669. doi: 10.1080/10511482.2020.1839936.

Salom Carrasco, J. y Pitarch Garrido, M. D. (2021). Cambios económicos, movilidad residencial y gentrificación en la ciudad de Valencia (20142017). Documents d'Anàlisi Geogràfica, 67(3), 1-40. doi: 10.5565/rev/dag.661.

Sequera Fernández, J. (2020). Gentrificación: capitalismo cool, turismo y control del espacio urbano. Madrid, España: Los Libros de la Catarata.

Seymour, E. y Akers, J. (2020). Our Customer Is America: Housing Insecurity and Eviction in Las Vegas,
Nevada's Postcrisis Rental Markets. Housing Policy Debate, 31(3-5), 516-539, 1-24. doi:10.1080/1 0511482.2020 .1822903$.

Soederberg, S. (2018). The rental housing question: Exploitation, eviction and erasures. Geoforum, 89, 114-123. doi: 10.1016/j.geoforum.2017.01.007.

Solana-Solana, A.; Ortiz Guitart, A.; López-Gay, A. (2021). "Me están echando de mi casa". Repercusiones personales y sociales de la inseguridad residencial en Barcelona. Papers: revista de sociologia, 106(1), 139-62. doi: 10.5565/rev/papers.2842.

Valero-Matas, J. A., Coca, J. R. y Valero-Oteo, I. (2014). Análisis de la inmigración en España y la crisis económica. Papeles de población, 20(80), 9-45.

Vives-Miró, S., Rullán, O. y González-Pérez, J. M. (2018). Cartografías de los desplazamientos por desposesión de vivienda. Desahucios y ejecuciones hipotecarias en Palma a través de su geohistoria. Scripta Nova. Revista Electrónica de Geografía y Ciencias Sociales, 22(591), 1-26. doi:10.1344/ sn2018.22.19774.

Vives-Miró, S. y Rullán, O. (2017). ¿Desposesión de vivienda por turistización? Revalorización y desplazamientos en el centro histórico de Palma (Mallorca). Revista de Geografía Norte Grande, (67), 53-71. doi: 10.4067/S0718-34022017000200004.

Yrigoy, I. (2017). Airbnb en Menorca: ¿Una nueva forma de gentrificación turística? Localización de la vivienda turística, agentes e impactos sobre el alquiler residencial. Scripta Nova. Revista Electrónica de Geografía y Ciencias Sociales, 21, 1-31. doi: 10.1344/sn2017.21.18573.

Yrigoy, I. (2019). Rent gap reloaded: Airbnb and the shift from residential to touristic rental housing in the Palma Old Quarter in Mallorca, Spain. Urban Studies, 56(13), 2709-2726. doi:10.1177/0042098018803261. 